Florida International University

FIU Digital Commons

6-28-2019

\title{
Male Offenders Perspectives on Contextual and Proximal Events associated with Incidents of Domestic Violence
}

Sharon M. Aaron

Florida International University, saaro001@fiu.edu

Follow this and additional works at: https://digitalcommons.fiu.edu/etd

Part of the Criminology Commons, Domestic and Intimate Partner Violence Commons, Health Policy Commons, Politics and Social Change Commons, Public Policy Commons, Social Control, Law, Crime, and Deviance Commons, Social Policy Commons, Social Welfare Commons, and the Social Work Commons

\section{Recommended Citation}

Aaron, Sharon M., "Male Offenders Perspectives on Contextual and Proximal Events associated with Incidents of Domestic Violence" (2019). FIU Electronic Theses and Dissertations. 4237.

https://digitalcommons.fiu.edu/etd/4237

This work is brought to you for free and open access by the University Graduate School at FIU Digital Commons. It has been accepted for inclusion in FIU Electronic Theses and Dissertations by an authorized administrator of FIU Digital Commons. For more information, please contact dcc@fiu.edu. 
FLORIDA INTERNATIONAL UNIVERSITY

Miami, Florida

\section{MALE OFFENDERS' PERSPECTIVES ON CONTEXTUAL AND PROXIMAL EVENTS ASSOCIATED WITH INCIDENTS OF DOMESTIC VIOLENCE}

A dissertation submitted in partial fulfillment of

the requirements for the degree of DOCTOR OF

PHILOSOPHY

in

SOCIAL WELFARE

by

Sharon Aaron

2019 
To: Dean Tomás R. Guilarte

Robert Stempel College of Public Health and Social Work

This dissertation, written by Sharon Aaron and entitled, Male Offenders' Perspectives on Contextual and Proximal Events Associated with Incidents of Domestic Violence, having been approved in respect to style and intellectual content, is referred to you for judgment.

We have read this dissertation and recommend that it be approved.

Paul H. Stuart

Nicole Ruggiano

Maria Elena Villar

Richard Beaulaurier, Major Professor

Date of Defense: June 28, 2019

The dissertation of Sharon Aaron is approved.

Dean Tomás R. Guilarte Robert Stempel College of Public Health and Social Work

Andrés G. Gil Vice President for Research and Economic Development and Dean of the University Graduate School

Florida International University, 2019 
C Copyright 2019 by Sharon Aaron

All rights reserved. 


\section{DEDICATION}

To my husband, Bill, whose moral support and sacrifices, great and small, made it possible for me to complete this dissertation.

To my daughter, Melanie, for indulging the precious time not spent together. 


\section{ACKNOWLEDGMENTS}

I wish to express sincere gratitude to my committee chair and committee members:

First, to Richard Beaulaurier, my advisor, who good naturedly tolerated my angst, and for whose patience, guidance and expertise I am truly grateful.

To Paul Stuart, who encouraged me to undertake this journey, and whose keen eye for details ensured the quality and thoroughness of my efforts.

To Nicole Ruggiano, who guided my thinking, and broadened my scope-and whose proficiency in organization helped me write coherently.

To Maria Elena Villar, whose enthusiasm, support, and advice made this pursuit less daunting, and whose feedback provoked much thinking.

And to others who helped tremendously along the way, my sincere gratitude:

To Miriam Potocky, who made statistics accessible to me and without whose teaching skills I could not have advanced in this quest.

To David McGriff, who generously granted me access to the study population and supported its purpose. 
ABSTRACT OF THE DISSERTATION

\title{
MALE OFFENDERS' PERSPECTIVES ON CONTEXTUAL AND PROXIMAL EVENTS ASSOCIATED WITH INCIDENTS OF DOMESTIC VIOLENCE
}

\author{
by
}

Sharon Aaron

Florida International University, 2019

Miami, Florida

Professor Richard Beaulaurier, Major Professor

Domestic violence is a serious public health problem in the United States; one which has proven intractable to researchers working on theory development and on effective prevention interventions. Although much has been reported from the perspectives of battered women, there are few studies that examine the perspectives of male offenders. In particular, there has been a call for more research on contextual and proximal events associated with incidents of domestic violence from the male offenders' perspective. In this study, ten male offenders were interviewed to address this need. Interviews were analyzed using grounded theory method to identify themes in the participants' accounts of the violent incidents for which they were arrested or otherwise mandated to batterer intervention programs. According to the accounts of participants, the domestic violence in their cases is situational in nature, as opposed to the much more dangerous coercive controlling violence. Themes that emerged were: female primary aggressor initiating the violence; adverse financial impacts; perceptions of bias in favor of women by the justice system; offenders' limited insight; and childhood trauma.

Research has demonstrated that childhood traumatic experiences are extremely common 
and that there is a significant relationship between childhood trauma and adult domestic violence. Themes that emerged in this study support those found in similar studies; however, domestic violence theory and intervention could be enhanced by investigating the neurobiology of trauma and trauma-informed treatment in future efforts to understand and address this prevalent public health problem. 


\section{TABLE OF CONTENTS}

CHAPTER PAGE

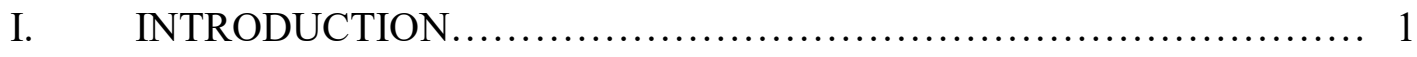

II. LITERATURE REVIEW......................................... 12

Domestic Violence Theory Development............................ 12

Challenges to U.S. Justice System Batterer Intervention Programs............ 17

Research on Types of Violence and Types of Offenders.....................19

Emerging Comprehensive Domestic Violence Frameworks................. 24

III. INTIMATE PARTNER VIOLENCE CONTEXTUAL FRAMEWORK .... 32

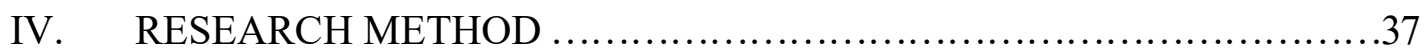

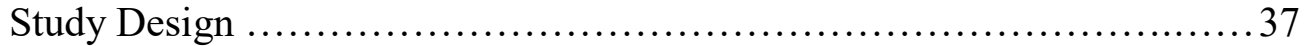

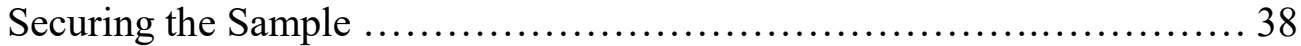

Data Collection Procedures .............................................. 41

Data Analysis ......................................................... 46

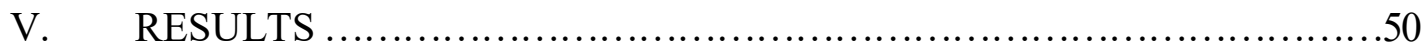

Demographic Information........................................... 50

Distal Contextual Findings............................................. 53

Contextual Factors About Female Partners Reported by Participants.........56

Precipitating Events.......................................................... 60

Emergent Themes................................................... 62

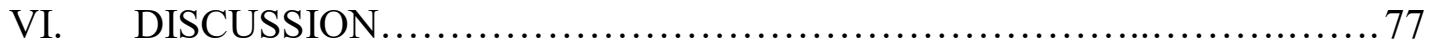

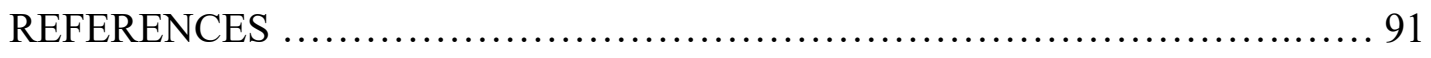

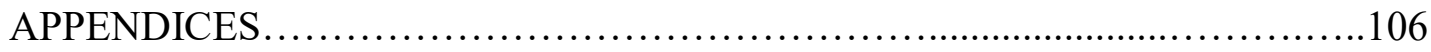

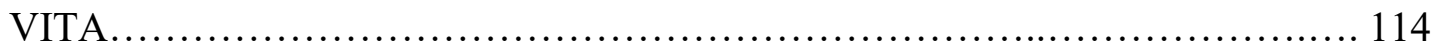




\section{CHAPTER I: INTRODUCTION}

This study explored male domestic violence offenders' perspectives of proximal, contextual, and historical events associated with incidents of domestic violence against their female partners. Findings were compared to a contextual framework posited by Bell \& Naugle (2008), described later in this paper. Research is needed from the perspective of male domestic violence offenders regarding proximal and contextual events associated with violent incidents. Such research has been called by for by scholars as essential in ongoing efforts to build comprehensive theory (Bell \& Naugle, 2008; Flink \& Paavilainen, 2008; Flynn \& Graham, 2010; Frye \& Karney, 2006; Holtzworth-Munroe, Stuart, Meehan, Herron \& Rehman, 2003; O’Leary \& Smith-Slep, 2006).

Domestic violence scholars have argued that no single theory provides a comprehensive understanding of this phenomenon, and existing theories often fail to account for contradictory research findings (Babcock, Green \& Robie, 2004; Corvo, Dutton \& Chen, 2008; Feder, Wilson \& Austin, 2008; Smedslund, Dalsbø, Steiro, Winsvold, Clench-Aas, 2007). Domestic violence theory development also is challenged by a deficiency in predictive power (Birkley \& Eckhardt, 2015; Frye \& Karney, 2006). Gaps in knowledge about the etiology and effective intervention related to domestic violence persist, and are exacerbated by problems with definition, lack of cohesive theory, and a lack of well controlled treatment outcome studies (Feldman \& Ridley, 2006; Leisenring, 2008; Mears \& Visher, 2005; Shorey, Cornelius \& Bell, 2008)

In addition, the development of effective rehabilitation programs and efforts to reduce domestic violence, require a thorough understanding of domestic violence (Feder, 
Forde, Davis, Maxwell \& Taylor, 2003; Neal \& Edwards, 2015; Reitz, 1999, Rhatigan, Moore \& Street, 2005; van Niekerk \& Boonzaier, 2014; Wood, 2004).

Studies designed to address gaps in knowledge have identified different types of abusers, as well as personality traits that interact differently with intervention approaches (Buttell, 2002; Holtzworth-Munroe, Stuart, Meehan, Herron \& Rehman, 2003; Kelly \& Johnson, 2008; Saunders, 1996). However, scholars have argued that research related to the characteristics of batterers and types of violence has not contributed much to the understanding of the incidents themselves, and that in-depth descriptions of proximal precipitants could help with theory development (Frye \& Karney,2006; O'Leary \& Smith-Slep, 2006; Shorey, Cornelius \& Bell, 2008).

\section{Significance of the Study}

In addition to the need for in-depth descriptions of proximal precipitants, a gap in knowledge has been identified regarding the perspectives of male offenders (Bell \& Naugle, 2008; Flink \& Paavilainen, 2008; Flynn \& Graham, 2010; Holtzworth-Munroe, Stuart, Meehan, Herron \& Rehman, 2003; Walker, Bowen \& Brown, 2012; Wood, 2004). Research regarding the perspectives of domestic violence offenders may contribute to the understanding of how to effectively intervene in relationships affected by domestic violence (Flink \& Paavilainen, 2008; Reitz, 1999; van Niekerk \& Boonzaier, 2014; Wood, 2004). Flynn \& Graham (2010) noted that few studies have examined the reasons and explanations for violence from the perspectives of those who are responsible for the violence, which, “...can provide important insight into IPV [intimate partner violence $\mathrm{a} / \mathrm{k} / \mathrm{a}$ domestic violence] that may not be apparent from more objective measures of risk factors" (p. 240). 
Flynn \& Graham (2010) indicated that the perspectives of domestic violence offenders could contribute information about predispositions such as locus of control. According to Flynn \& Graham (2010) offenders' descriptions of incidents can reveal much about the nature of their aggressive behavior. For example, offenders' accounts of aggressive incidents can reveal whether their behavior is characterological—and therefore more resistant to change. Similarly, offenders' accounts can reveal whether their behavior was situational — which would provide clues about where and how to intervene to help them change their violent behavior. Some have argued that a lack of research on male batterers' perspectives has led to limitations in treatment (Reitz, 1999; van Niekerk \& Boonzaier, 2014; Wood, 2004).

Relatedly, information about the context in which the violence occurred is needed, because of its potential to influence incidents (Bell \& Naugle, 2008; Flink \& Paavilainen, 2008; Flynn \& Graham, 2010; Holtzworth-Munroe, et al., 2003). In their review of domestic violence theories and limitations, Bell \& Naugle (2008) recommended that future research should "address contextual and proximal events associated with IPV [domestic violence] episodes" (p.1101).

In addition to proximal events and context, distal attributes were explored during the participants' interviews to account for previous research that indicated that a relationship exists between adolescent emotional and behavioral problems and later perpetration of domestic violence (Ehrensaft, Moffitt, Caspi ,2004; Neal \& Edwards, 2015; Olsen, Parra \& Bennett, 2010). Likewise, domestic violence in participants' families of origin was explored (Elmquist, Shorey, Labrecque, Ninnemann, Zapor, Febres, J., ... Stuart, 2016; Ehrensaft, Cohen, Brown, Smailes, Chen, \& Johnson, 2003; 
Olsen, Parra, \& Bennett, 2010). Severity of violence and severity of injuries related to domestic violence have been identified in previous studies as important indicators of lethality risk (Campbell, Webster, Koziol-McLain, Block, Campbell, Curry...Laughon, 2003; Ehrensaft, Moffitt \& Caspi, 2004; Kingsnorth, 2007), and those two factors were also examined in this study. In sum, there is a need to understand what happened and why, and under what circumstances - according to the men who engaged in violence against their female partners.

\section{Specific Aims}

This study sought to contribute to the need for understanding proximal precipitants and contextual factors from the perspectives of men who have been courtordered to batterer intervention programs (BIPs) in Miami-Dade County, Florida. Through semi-structured interviews, the study focused upon these aspects of domestic violence incidents. The study participants' perspectives were analyzed according to the contextual framework posited by Bell \& Naugle (2008) and were also examined through the lens of Malle's (2007) concepts related to underlying personal and social motivations for behavior explanations--both described later in this paper. Specifically, this study aimed to:

1) Identify perspectives of proximal and contextual events of violent episodes among men arrested or otherwise court referred to Batterer Intervention Programs (BIPs) for domestic violence against their female intimate partners (male offenders); 
2) Examine proximal, contextual and historical events identified by study participants and analyze their fit with the existing contextual framework described by Bell \& Naugle (2008);

3) Examine whether any offenders' perspectives of precipitants of domestic violence are correlated with severity of violence; particularly in terms of use of weapon and severity of injuries.

\section{The Extent of the Problem}

Domestic violence has been identified as a public health crisis in the United States and impacts people of all types of demographic backgrounds (Max, Rice, Finkelstein, Bardwell \& Leadbetter 2004; Hasstedt \& Rowan, 2016; U.S. Department of Health and Human Services, 2014). Violence between intimate partners represented $15 \%$ of all crimes nationwide during 2003-2012. Most of the violence between intimates that was reported was committed against women; 76\% (Truman and Morgan, 2014). According to the national Bureau of Justice crime statistics, $39 \%$ of the 3,032 homicides of females during 2010 were committed by an intimate partner (U.S. Department of Justice, Bureau of Justice Statistics, 2012).

Although domestic violence fatalities are documented in the U.S., non-fatal domestic violence incidents are difficult to ascertain; incidents are documented through surveys (National Intimate Partner and Sexual Violence Survey, 2013; National Crime Victimization Survey, 2016). Gathering surveillance data on intimate partner violence is complicated by the ways in which information is collected, the multiple sources from which it is reported, and the social/emotional constraints to reporting. Police gather data based on incidents, making it difficult to determine the number of individuals affected. 
Conversely, hospitals maintain records according to individual patients (Salzman, Fanslow, McMahon \& Shelley, 1999). The result of these two methods of data collection is that multiple incidents can represent one person (when reported to police), and one person can represent multiple incidents (when presenting at hospitals).

Furthermore, incidents of domestic violence are reported to the Federal Bureau of Investigation (FBI) by local police departments annually in the form of specific crimes, rather than as domestic violence crimes. In other words, domestic violence incidents are reported to the FBI as crimes such as battery, aggravated battery, breaking and entering, robbery, false imprisonment, kidnapping, arson, stalking, attempted murder, and others, which are published in its Uniform Crime Statistics. Although there is a definition of domestic violence in law, there is no crime specifically known as domestic violence (Salzman, Fanslow, McMahon \& Shelley, 1999).

Further exacerbating the issue of gathering accurate incidence and prevalence of domestic violence are issues related to battered women themselves. Women presenting at emergency departments do not always indicate that their injuries are related to domestic violence. Sometimes this can be because the topic is taboo; some women feel shame and guilt which inhibits self-disclosure of victimization. Cultural and religious factors can inhibit people from reporting, and people in same sex relationships must "out" themselves to strangers if they report domestic violence (and face possible discrimination). Other concerns relate to the dynamics of domestic violence relationships, such as fear of adverse repercussions and retaliation from the abuser or the abuser's family, or her own family. In addition, immigrant women, seasonal workers and undocumented women may want to avoid interaction with governmental or other 
institutions out of real or inaccurate beliefs that they will face legal problems or deportation (National Coalition Against Domestic Violence, 2018).

Impact of domestic violence on women. The National Intimate Partner and Sexual Violence Survey (NIPSV) is a nationally representative random digit dial telephone survey of men and women aged 18 and over (Breiding, Chen \& Black, 2014). According to NIPSV responses, approximately one in five (22.3 percent) women have suffered severe physical violence by their intimate partners, and nearly half have experienced psychological aggression (Breiding, Chen \& Black, 2014). Among all the women who were murdered in the U.S. between 2003 and 2012, approximately one-third (34 percent) were killed by a current or former male partner, compared to 2.5 percent of murdered males killed by a female partner during that same period (Uniform Crime Reports, 2014).

Economic impact of domestic violence in the U.S. The economic impact of domestic violence includes medical costs and loss of worker productivity (Olsen, Parra \& Bennett, 2010). The most recent estimates of public costs associated with domestic violence exceed $\$ 8$ billion annually. This estimate does not include costs associated with the criminal justice system (Max, Rice, Finkelstein, Bardwell \& Leadbetter, 2004). According to the Centers for Disease Control, people who experience severe domestic violence, "lose nearly 8 million days of paid work - the equivalent of more than 32,000 full-time jobs-and almost 5.6 million days of household productivity each year" (Centers for Disease Control and Prevention, 2003). 


\section{Domestic Violence: Associated Terms and Relevant Constructs}

Domestic Violence has been variously referred to as spouse assault, partner abuse, partner violence, marital violence, and intimate partner violence (IPV) (Breiding, Basil, Smith, Black \& Mahendra, 2015; Carney \& Barner, 2012; Holtzworth-Munroe, Stuart, Meehan, Herron \& Rehman, 2003; Kropp, Hat, Webster \& Eaves, 1999). Below is a review of definitions of associated terms for domestic violence and of constructs that have been developed in relation to that particular violence between individuals that has also been known as domestic violence.

Domestic violence. Del Martin (aka Dorothy Martin), activist and co-founder of the first national lesbian organization in the U.S. (Daughters of Bilitis in 1955) introduced the term domestic violence in 1975 at the meeting of the National Organization of Women (NOW) National Task Force on Battered Women/Household Violence.

This form of violence against women was seen by feminist activists as one part of society's overall cultural and institutionalized oppression of women. Their conceptualization of domestic violence was part of a larger feminist liberation agenda, that included policy changes to reduce women's dependence upon men, which was viewed as critical to supporting a woman's ability to free herself from an abusive relationship.

Issues such as equal pay, socialized high quality child care, universal health care, Aid to Dependent Children, Social Security benefits for homemakers/stay-at-home mothers, reproductive freedom, affirmative action and other reforms to support women's paid labor were among the women's liberation agenda of the 1970s (Ferraro, 1996). 
Thus, the terms battered women and domestic violence are associated with the second wave women's rights movement of the 1970s, and shelter activists sought reforms based on the Equal Protection Clause of the Fourteenth Amendment to the United States Constitution. In this case, the women's liberation and shelter activists argued that violence committed by intimates should be treated the same as if committed by strangers.

Battered women / batterers / battering. The activists of the women's shelter movement of the 1970s coined "battered women," as a way define victims of a particular kind of violence, which was formerly known as wife beating. According to Ellen Pence, a renowned activist of the time, "The word, battering, was to signify a pattern of coercive control, intimidation, and oppression that women often experienced at the hands of their male lovers and spouses" (Pence \& Dasgupta, 2006, p.1). From this definition, men who battered their female lovers and spouses became known at "batterers."

Intimate partner violence (IPV). A commonly recognized definition is the one developed by the Centers for Disease Control ("CDC") and cited in its Intimate Partner Surveillance: Uniform Definitions and Recommended Data Elements, Version 2:

A pattern of abusive behavior in any relationship that is used by one partner to gain or maintain power and control over another intimate partner. Domestic violence can be physical, sexual, emotional, economic, or psychological actions or threats of actions that influence another person. This includes any behaviors that intimidate, manipulate, humiliate, isolate, frighten, terrorize, coerce, threaten, blame, hurt, injure, or wound someone.

(Breiding, Basile, Smith, Black, Mahendra, 2015).

Version 1 of the CDC Uniform Definitions stated: "The term 'intimate partner violence' (IPV) describes physical, sexual, or psychological harm by a current or former partner or 
spouse. This type of violence can occur among heterosexual or same-sex couples and does not require sexual intimacy" (Salzman, Fanslow, McMahon \& Shelley, 1999).

Domestic violence offender / batterer. These two terms are synonymous and refer to the aggressor in a relationship characterized by domestic violence. (Jackson, Feder, Forde, Davis, Maxwell \& Taylor, 2003).

Florida law. Domestic violence is broadly defined in Florida law and includes violence between parents and children, people with a child in common, and other cohabitants.

Florida Statute: 741.28 Domestic violence; definitions. - As used in ss. 741.28-741.31:

(1) "Department" means the Florida Department of Law Enforcement. (2) "Domestic violence" means any assault, aggravated assault, battery, aggravated battery, sexual assault, sexual battery, stalking, aggravated stalking, kidnapping, false imprisonment, or any criminal offense resulting in physical injury or death of one family or household member by another family or household member.

(3) "Family or household member" means spouses, former spouses, persons related by blood or marriage, persons who are presently residing together as if a family or who have resided together in the past as if a family, and persons who are parents of a child in common regardless of whether they have been married. With the exception of persons who have a child in common, the family or household members must be currently residing or have in the past resided together in the same single dwelling unit.

(4) "Law enforcement officer" means any person who is elected, appointed, or employed by any municipality or the state or any political subdivision thereof who meets the minimum qualifications established in s. $\underline{943.13}$ and is certified as a law enforcement officer under s. 943.1395 .

History.-s. 1, ch. 94-134; s. 1, ch. 94-135; s. 1, ch. 95-195; s. 4, ch. 97-155; s. 9, ch. 2002-55.

(Florida Statutes, 2011).

Partner abuse. A term preferred by some researchers who argue that 'intimate' implies a relationship that is warm, cherished, close and friendly — which is in contrast to the assumed nature of the relationship that is characterized by abuse (Hamel, 2010) 
Partner violence. A term used to depict domestic violence between two adults who are engaged in a relationship either by marriage, co-habitation, or expectation of love or affection (Heise, 2011).

Term used in this study. As noted above, physical, sexual and psychological aggression have been identified as components of abuse in intimate relationships; however, for purposes of this study, the term for this phenomenon is the one that is used in the Florida Statute, i.e., domestic violence, and specifically violence involving physical injury, and that also encompasses domestic violence as conceived by the 1970s women's shelter activists; i.e., male perpetrated violence against a female intimate partner. 


\section{CHAPTER II: LITERATURE REVIEW}

\section{Domestic Violence Theory Development.}

Domestic violence is a complex social and public health problem without a comprehensive theory for prediction, intervention, or primary prevention (Babcock, Green \& Robie, 2004; Brown, James \& Taylor, 2010; Corvo, Dutton \& Chen, 2008; Davis \& Taylor, 1999; Dutton, 2006; Feder, Wilson \& Austin, 2008; Gondolf, 2000; Smedslund, Dalsbø, Steiro, Winsvold, Clench-Aas, 2007; Yllo, 2005). Gaps in knowledge about the etiology and effective intervention persist, and are exacerbated by problems with definition, lack of cohesive theory and few well controlled treatment outcome studies (Feldman \& Ridley, 2006). A variety of approaches have been explored in the continuing effort to develop comprehensive domestic violence theory and to find effective interventions that will support theory development. Below is a review of such approaches.

Risk factors research. Risk for perpetration of domestic violence was an early focus of research in this field and continues to be an area of study. The concept of risk factor has been defined by Jenson \& Fraser (2006) as: “... any event, condition or experience that increases the probability that a problem will be formed, maintained, or exacerbated" (p. 6).

The application of risk factors to domestic violence. Research has focused on risk factors for domestic violence perpetration in an effort to predict and prevent incidents (Belfrage \& Strand, 2008; Campbell, Webster, Koziol-McLain, Block, Campbell, Curry ... Laughon, 2003; Cattaneo, Bell, Goodman \& Dutton, 2007; Echeburúa, Fernández-Montalvo, De Corral \& López-Goñi, 2009; Forgey, Badger \& 
Krase, 2011; Kingsnorth, 2006; Krop \& Hart, 2000). One study on risk of recidivism found factors such as “....use of a weapon, the offender's prior arrest for any offense, and the presence of a protective order at the time of the precipitating incident all predicted rearrest for intimate violence within an 18-month follow-up period" (Kingsnorth, 2006, p.917).

Echeburúa, et al. (2009), developed a scale to assess risk for severe IPV and intimate partner femicide, and found four risk factors to be particularly salient due to their high discriminative capacity, as follows:

1. ...severe threats or threatening to kill;

2. threatening with dangerous objects or with weapons of any kind;

3. very intense jealousy or controlling behaviors toward partner;

4. justification of violent behavior due to aggressor's own state

(alcohol, drugs, stress) or to victim's provocation (p. 936).

In their conceptualization of IPV risk factors, Corvo \& de Lara (2011) reported that certain specific "individual-level risk factors" are associated with IPV, such as (1) particular family of origin influences, (2) poor impulse control, (3) personality disturbance, (4) neuropsychological vulnerability, (5) substance abuse, and (6) intimacy dysfunction (p. 78).

Other efforts to predict and prevent domestic violence include the development of risk assessment instruments; notably the Danger Assessment Tool (Campbell, Webster \& Glass, 2009), the Femicide Scale (Kerry, 1998), the Spousal Assault Risk Appraisal Guide (Kropp \& Hart, 2000) and the Brief Spousal Assault Form for the Evaluation of Risk (Belfrage \& Strand, 2008). Most widely used in studies is the Revised Conflict 
Tactics Scales (CTS-2) (Straus, Hamby \& Warren, 2003) and the Conflict Tactics Scales (CTS) (Straus, Hamby, Boney-McCoy \& Sugarman, 1996). The CTS and CTS2 are behavioral measures, deliberately excluding attitudes, emotions and appraisal of the behaviors. Straus (2007) argued that women do not endorse items related to such constructs in most assessments, and therefore, should be asked about such matters during interviews.

Forgey, Badger \& Krause (2011) conducted a review of domestic violence risk assessment instruments, and "concluded that these assessments were imperfect at best" and that they weakly predicted recidivism (p. 335). Their recommendation was to use "multiple methods and multiple sources" to assess risk, rather than an aggregation of risk factors (p. 336). Given that an extensive variety of risk factors has been identified, and that they have not produced an overarching theory for understanding, predicting, or for accounting for contradictory findings, it is important to cast a wider net in the investigation of domestic violence.

\section{Theories Adopted by U. S. Justice System for Domestic Violence Treatment}

Because there is no overarching theory for understanding domestic violence, the criminal and civil courts in the U.S. drew from existing theories to design interventions for domestic violence offenders, and three theories in particular have been pressed into service: social exchange / deterrence, social learning, and feminist theory (Danis, 2003; Sherman, 2003).

Social exchange theory. Social exchange theory explains human behavior in terms of a pursuit of awards and avoidance of costs (e.g., punishments) (Blau, 1964), and the concept of deterrence in criminal justice is predicated upon this theory. In the case of 
domestic violence offenses, an individual theoretically considers whether the costs of using violence against a family member outweighs the rewards. Harsh penalties and the threat of incarceration are presumed to be more costly, thereby deterring violence against family members. This application of social exchange / deterrence has been criticized on the grounds that people who behave violently toward a family member are acting emotionally and not rationally. Therefore, a rational consideration of awards and costs does not come into play during an incident of domestic violence (Sherman, 2003).

Social learning theory. Similar to the awards/costs concept posited in social exchange theory, social learning theory (Bandura, 1963) includes the idea of people learning to be violent based on the experience of reward or punishment (reinforcement) immediately after their violent behavior. According to social learning theory, violence also can be learned through witnessing others' violent behavior (modeling). This vicarious learning also has been labeled "intergenerational transmission of violence" (Elmquist, et al., 2016; Widom, 1989). Ehrensaft, Cohen, Brown, Smailes, Chen, \& Johnson, (2003) found that conduct disorder in childhood was more closely associated with perpetrating domestic violence; in adulthood; however, witnessing violence between parents also correlated.

Feminist model. Another intervention model, commonly known as the Duluth model (Pence \& Paymar, 1993; Yllo, 2005), is feminist-based and targets patriarchal beliefs. The object of the intervention is to hold the men accountable for their violence and to enhance victim safety. The intervention uses a psychoeducational group format and includes identification of controlling tactics used by offenders through a graphic known as the Power and Control Wheel (See Figure 1). 
According to this model, men who batter their female partners are seen as products of gendered socialization in a patriarchal society that oppresses women. Their violence is viewed as learned behavior that is socially reinforced, and therefore, reeducation is required to change (Bandura, D. Ross, S. Ross, 1963; Tsai, 2000). This approach represents the influence of battered women advocates, (Healey, Smith, O'Sullivan \& Abt Associates, 1998), but does not reflect consensus among scholars about causes of battering or effective treatment (Bowen, 2010; Cogan \& Porcerelli, 2003; Davis \& Taylor, 1999; McCollum \& Stith, 2008; Musser \& Murphy, 2009; Lawson, 2010; Saunders, 1996).

Cognitive behavioral treatment. Combined with the feminist model, cognitive behavioral techniques are widely employed in batterer intervention programs (BIPs). This expands the feminist Duluth model's psychoeducational approach in group format with content that includes cognitive behavioral techniques (Carney \& Buttel, 2006; Healey, Smith, O’Sullivan \& Abt Associates, 1998; Lawson, 2010; Sonkin, Martin \& Walker, 1985). Cognitive behavioral therapy is a treatment approach that aims to change behavior as well as thoughts and beliefs that contribute to undesired behaviors. As it applies to domestic violence, participants are helped to identify and examine maladaptive cognitions and assumptions that precede violence, in order to disrupt the procession of events that leads to violent behavior (Beck 1979).

Batter traits and treatment. Saunders (1996) was interested in whether matching offender traits with cognitive-behavioral therapy or with insight-oriented therapy (psychodynamic theory) would result in better outcomes. Psychodynamic theory interprets domestic violence as either: (1) reenactment of past traumatic experiences; (2) 
attempts to defend against feelings of vulnerability, or (3) displacement of anger onto others. This theory and process is described more fully by Cogan and Porcerelli (2003).

In Saunders' study, Process-Psychodynamic Treatment, which is unstructured and non-didactic, was compared for relative effectiveness with the mainstream FeministCognitive-Behavioral Treatment, which combines skills-training and gender role resocialization in a highly structured format. The main outcome measure was partners' reports of the abusers' behavior after treatment. Saunders (1996) reported that:

- Men with dependent traits had lower recidivism with Process Psychodynamic Treatment;

- Men with antisocial traits were less likely to be violent after treatment if they received Feminist Cognitive Behavior Treatment;

- Men with substance abuse and hypomania (impulsivity) had lower recidivism in Feminist Cognitive Behavior Treatment condition.

Saunders's study suggests support for tailored treatment for domestic violence offenders. Matching offender traits to particular treatment approaches is thought to result in better outcomes (Dutton, 1993; Holtzworth-Munroe, Stuart, Meehan, et al., 2003), however further investigation is needed.

\section{Challenges to U.S. Justice System Batterer Intervention Programs}

Interventions based on these models are challenged by poor retention rates and inconclusive efficacy (Babcock, et al., 2004; Feder \& Wilson, 2005; Gondolf, 2009; Price \& Rosenbaum, 2009). In one study of 620 men mandated to BIPs under threat of incarceration, 50\% did not complete, or never attended at all (Gondolf, 2002). Another study of BIPs on offender recidivism found that $41 \%$ reported that the men re-assaulted 
during the 30-month follow-up period (Gondolf, 2000). Furthermore, nearly two-thirds of the re-assaults occurred within the first 6 months after treatment, and "about" $20 \%$ of the men repeatedly re-assaulted their partners. Despite many years of targeted and intensive responses to the problem, recidivism remains high-33\% to $66 \%$ (Jones \& Gondolf, 2002; Ventura \& Davis, 2005).

In sum, theories adapted for Batterer Intervention Programs have been generally ineffective and these programs suffer from high attrition rates. Babcock, et al. (2004) reported in their meta-analysis of domestic violence treatment that, "Within this study and across the domain of studies to date, effect sizes due to all types of interventions are small" (p. 1041). Given the inadequate results of these intervention models to date, Catlett, Toews and Walilko, (2010) argued for treatment modalities that match personal profiles and that integrate cultural norms. Research aimed at understanding batterer traits and batterer types and their treatment interactions has been conducted and is discussed below. 
Figure 1. Power and Control Wheel

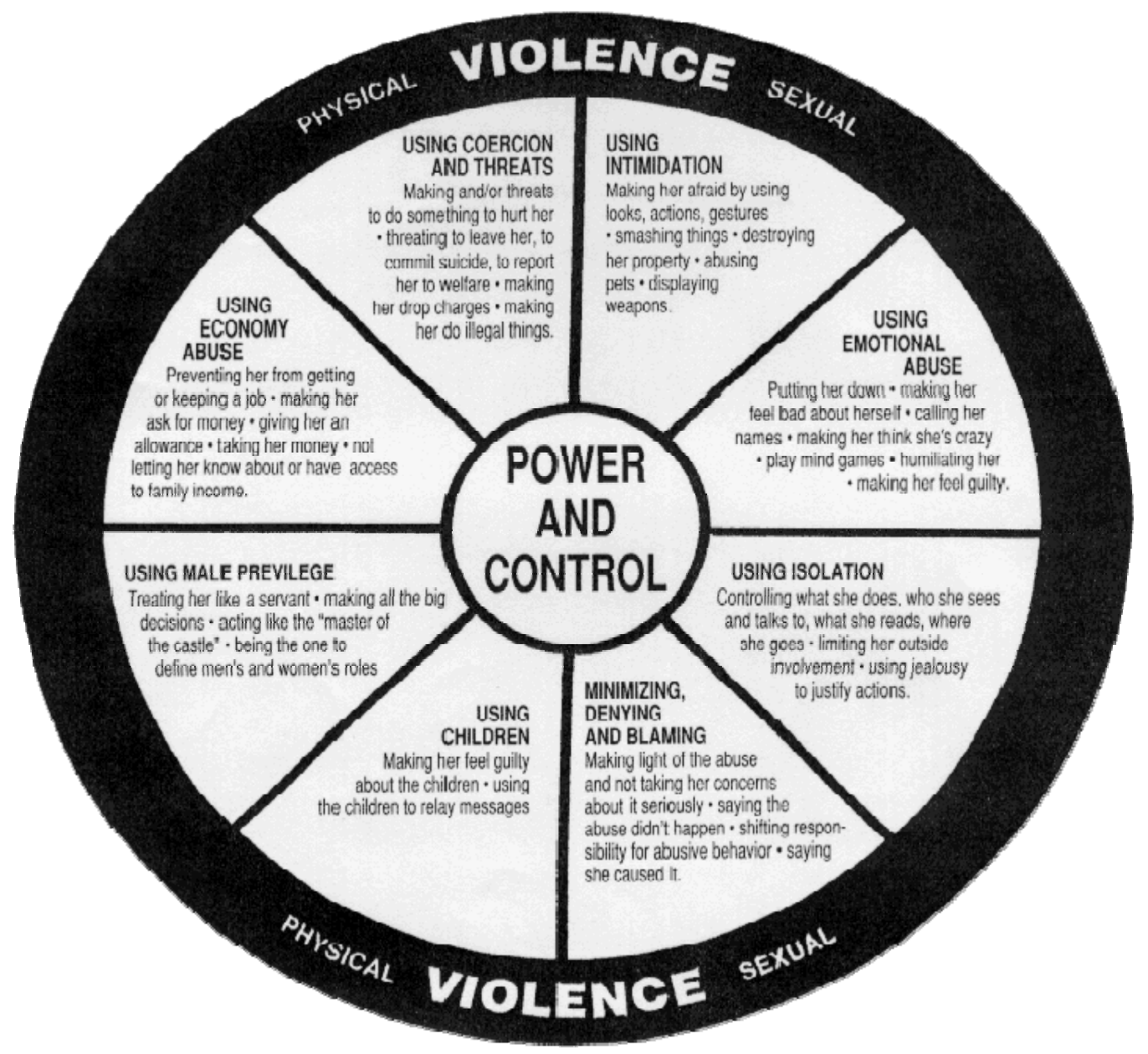

Domestic Abuse Intervention Program

Pence and Paymar, 1993

Reproduced with permission

\section{Research on Types of Domestic Violence and Types of Offenders}

Batterer traits and types. There is research suggesting that certain personality styles and disorders interact differently according to type of treatment provided. Studies differentiating among types of male batterers suggested that tailored interventions may improve outcomes (Carney \& Buttell, 2006; McCollum \& Stith, 2008; Mears \& Visher, 2005; Stith, Rosen, McCollum, \& Thomsen, 2004). 
Research was conducted among male abusers, who were classified according to the kind of childhood trauma they experienced and the resultant pathology. According to the studies, three general types were identified:

(1) severe childhood physical abuse tends to result in antisocial traits, including aggression and a dismissive attachment style;

(2) severe parental rejection tends to lead to borderline traits, with abusive and labile emotional expression, high dependency needs and preoccupied or ambivalent attachment style;

(3) low to moderate childhood abuse or low to moderate childhood parental rejection (relative to the other two groups of male abusers) tends to produce compulsive traits and poor communication skills and secure or preoccupied attachment style (Dutton \& Painter, 1993; Holtzworth \& Stuart, 1994; Holtzworth-Munroe, Stuart, Meehan, et al., 2003; Saunders, 1996).

Subtypes of batterers and psychopathology. The types described above focused on distal correlates in childhood, such as poor parental attachment patterns, and parental abuse.

Holtzworth-Munroe \& Stuart (1994) conducted a review of previously identified batterer types and classified them into three descriptive characteristics:

(1) severity and frequency of violence toward wife;

(2) generality of the husband's violence (i.e., violence limited to within the family or generally violent outside the family as well);

(3) the husband's psychopathology or personality disorder. 
From those three descriptive categories, Holtzworth-Munroe and Stuart (1994) proposed three subtypes of male batterers:

1. Family-only,

2. Borderline/Dysphoric, and

3. Generally Violent/Antisocial batterers.

They proposed that Family-Only batterers would engage in the least amount of marital violence and also would engage in the least amount of violence outside the family — and would exhibit little or no psychopathology.

In contrast, Borderline/Dysphoric batterers were expected to engage in moderate to severe wife abuse - and may also engage in violence outside the family. According to Holtzworth-Munroe and Stuart, this group would be the most psychologically distressed with emotional volatility, and most likely to exhibit traits of borderline personality disorder.

Finally, the Generally Violent/Antisocial batterers were thought to also engage in moderate to severe marital violence but would also be the most violent toward others outside the family. This group was considered to show symptoms of antisocial personality disorder, including criminal behavior and substance abuse.

Later studies supported Holtzworth-Munroe and Stuart's typologies, including correlates among the subtypes such as history of child abuse, negative peer relationships, witnessing abuse, developmental differences, social skills and attitudes toward women and toward violence (Holtzworth-Munroe, Stuart, Meehan, Herron \& Rehman, 2003; Waltz, Babcock, Jacobson \& Gottman, 2000). 
These subtypes were thought to provide guidance on treatment approach; however, a study by Langhinrichsen-Rohling, Huss and Ramsey (2000) found that clinicians were unable to reliably sort batterers into subtypes based on their police records and results from the Beck Depression Inventory and the Minnesota Multiphasic Personality Inventory. In other words, the information that the clinicians had about individual batterers' characteristics did not help them identify which typologies they fit in - and therefore, were not useful to clinicians for purposes of determining appropriate treatment.

Holtzworth-Munroe, et al. (2003) acknowledged that the research on typology has been largely confined to relatively distal correlates and predictors of violence such as childhood events. They recommended exploration of explanatory variables related to particular incidents of domestic violence.

This study aims to understand the context of incidents from the perspectives of male batterers in comparison to an existing proposed contextual framework (Bell \& Naugle, 2008), and also to explore whether other factors emerge.

Type of violence used by batterers. Some studies reported the existence of different types or patterns of domestic violence (Graham-Kevan \& Archer, 2003; Kelly \& Johnson, 2008; Holtzworth-Munroe, Stuart, Meehan, Herron \& Rehman, 2003; Johnson, 1995, Johnson \& Ferraro, 2000; Johnston \& Campbell, 1993; Lawson, 2010; Leone, Johnson \& Cohan, 2007).

For example, four types of violence have been identified:

1. Coercive Controlling Violence (also known as Intimate Terrorism) is described as a severe form of abuse including a pattern of emotionally abusive intimidation, 
coercion, control and social isolation as well as physical violence against one's intimate partner;

2. Violent Resistance is used to describe situations when victims of Coercive Controlling Violence react with violence in order to get the violence to stop or to stand up for themselves (Kelly \& Johnson, 2008, p. 479);

3. Situational Couple Violence does not have the characteristic patterns of Coercive Controlling Violence, nor is one partner afraid of the other; rather, violence in this type reportedly occurs due to conflictual circumstances, or as a result of 'hot topics' in the relationship;

4. Separation-Instigated Violence refers to violence that occurs for the first time in the relationship at the time of separation. Kelly \& Johnson (2008) believe that it is important to differentiate this type of violence from Situational Couple Violence and Coercive Controlling Violence - both of which are part of pre-existing violence in the relationship. Situational Couple Violence may occur during the process of separation, and violence in Coercive Controlling Violence may escalate and even become lethal when the violent partner feels threatened by loss of control due to separation (Kelly \& Johnson, 2008, p. 480).

According to Kelly \& Johnson (2008), it is possible that treatment programs are generally effective with some types of violence (such as Situational Couple Violence), but not with others (such as Coercive Controlling Violence).

There has been some hypothesizing about what type of treatment is appropriate for the different types of violence. For example, some men and women involved in Situational Couple Violence have been theorized to have poor communication skills, impulsivity, and high levels of anger, while for others the problem may be alcohol abuse. For Situational 
Couple Violence, couples' treatment may be effective. For those involved in Coercive Controlling Violence, the problem is believed to be rooted in severe personality disorders or mental illness and may call for the inclusion of a more psychodynamic approach to treatment. For others, the problem appears to be one of a deeply ingrained antisocial or misogynistic attitude that would be more responsive to a feminist psycho-educational approach (Stith, Rosen, McCollum, \& Thomsen, 2004).

Leisenring (2008) asserted, "if we cannot understand partner violence, we cannot develop a response that will successfully reduce and eradicate partner violence" (p. 463). Endeavors to further our understanding of domestic violence have led to more comprehensive theoretical models, which are described below.

\section{Emerging Comprehensive Domestic Violence Frameworks}

It is apparent that domestic violence represents an intransigent problem that is complex and multi-determined (Walker, Bowen, \& Brown, 2012; Sheehan, Thakor \& Stewart, 2012; Silvergleid \& Mankowski, 2006). In the past ten years, there has been some progress in building overarching frameworks aimed at predicting and preventing domestic violence, as well as integrating extant research.

\section{Flynn \& Graham (2010)}

Flynn and Graham reviewed research on offenders' and victims' explanations for domestic violence and proposed a three-level model for perceived reasons for such violence. Their three levels model was used to frame the review of research on perceived explanations for incidents of domestic violence. As posited by Flynn and Graham, Level 1 includes stable characteristics of the individuals, such as "background and personal attributes." Level 2 includes "current life circumstances," such as financial stressors, 
health problems and alcohol/substance abuse. Level 3 includes "immediate precursors or precipitators" of a violent incident (p. 242).

In their review, a search of "motive* or reason * or trigger*" among three databases yielded 16 empirical studies. Flynn and Graham (2010) found low endorsements for Level 1 background/childhood experiences and "large variability" for personal attributes, such as character and personality. Among the 16 studies reviewed, four included items specifically related to stress. Twenty to seventy-nine percent of male and female respondents endorsed varying kinds of stress associated with varying levels of severity of violence. Financial stress and marital stress were most commonly endorsed by the male perpetrators. With regard to Level 3, which is identified as "immediate precursors or precipitants to violence," a wide range of explanations was endorsed (p. 242).

However, Flynn and Graham (2010) noted that the explanations did have in common the belief that something one partner did caused the other partner to respond with violence. Most common among those reasons were: self-defense in reaction to their partners' aggression; retaliation for something their partners did; and infidelity. Anger was also commonly endorsed as a reason for violence, but anger does not provide insight about the underlying reason for violence. Flynn and Graham (2010) noted that other reasons for violence were cited but were "too ambiguous or did not represent a clearly defined category of reasons" for domestic violence (p. 247).

Flynn and Graham (2010) concluded that Levels 1 and 2 of their model were only reflected in a few of the studies reviewed. They recommended that development of future measures of perceived reasons for domestic violence should include items related 
to how the perpetrators and victims themselves view factors such as background, attitudes and personality. Further, Flynn and Graham speculate that stressors may be contextual influences on incidents of domestic violence, but not precipitants. They called for more standardization in conceptualization and specification of the proximity of perceived reasons for violence and for larger study samples.

In addition, Flynn \& Graham (2010) noted that few studies have examined the reasons and explanations for violence from those who are responsible for the violencethe aggressors — which, “...can provide important insight into IPV [domestic violence] that may not be apparent from more objective measures of risk factors" (p. 240). Furthermore, face-to-face interviews with male batterers have been reported to be more effective at eliciting fuller disclosure of violent behavior than written questionnaires (Anderson, Gillig, Sitaker, McCloskey, Malloy \& Grigsby, 2003).

\section{Finkel, Slotter, Pond Jr., DeWall, McNulty \& Atkins (2012)}

Finkel, et al. (2012) acknowledged extant research that has yielded many risk factors for domestic violence, as noted in the discussion of risk factor research. However, among the broad range of potential risk factors for domestic violence perpetration, Finkel, et al. noted that no method or process had been presented to identify the process by which potential risk factors culminate in an incident of domestic violence. In response, Finkel, et al., presented a framework posited to translate the risk literature on domestic violence into "process-oriented terms" (p. 533).

$I^{3}$ theory. The theory, at first labeled $\mathrm{I}^{3}$ (pronounced I-cubed), proposed that all risk factors stimulate domestic violence perpetration through three processes: impellance, inhibition, and instigation. That is, if a person's disposition inclines him to be aggressive, 
or if a certain situation exists that creates a psychological inclination toward aggression, then that person is thought to be impelled toward violence. However, impellance alone will not necessarily predict that domestic violence will occur. For an incident to occur, impellance is said to interact with the two other factors contemporaneously to create a "perfect storm" which results in violence (p. 534). For an incident to occur, inhibition must also be lowered, either through situational or dispositional features, and instigation must also occur. Instigation refers to the non-aggressive partner's behaviorindependent of her abusive partner - that serves to provoke his violence.

Studies to test $\mathbf{I}^{3}$. Finkel, et al. (2012) hypothesized that:

0 heightened impellance $\times$ lowered inhibition $\times$ instigation is the process by which an incident of domestic violence occurs. Four different studies were conducted by the team using the risk factor - dispositional aggressiveness - to test the interaction effect. According to Finkel, et al., translating ideas into empirically tested hypotheses requires conceptualizing the proposed predictors at three levels of analysis, for example:

1. instigation, impellance and inhibition form the process level;

2. risk factors, like provocation, dispositional aggressiveness, and executive control form the construct level;

3. specific operationalizations (e.g., insulting feedback to assess instigation, selfreported dispositional physical aggressiveness to assess dispositional aggressiveness, Stroop color-naming task performance to assess executive control) form the operation level.

(p. 534) 
In this example, provocation and insulting feedback represent instigation. Dispositional aggressiveness represents impellance and executive control through Stroop task performance represents capacity for inhibition.

Finkel, et al. (2012) conducted four different studies using different operationalizations and varied constructs—with dispositional aggressiveness as the risk factor. The strength of inhibition and of instigation were also varied. The results of all four studies confirmed that domestic violence perpetration was "stronger when inhibition was weak, rather than strong, especially in the presence of strong instigation," and "when inhibition was strong and instigation was weak, dispositional aggressiveness frequently failed to predict perpetration at all" (p. 545).

For an in-depth description of the methods and results of the four studies, see Finkel, et al. (2012). The research team noted the importance of incorporating impellance, instigation and inhibition factors into theoretical and empirical analyses of domestic violence perpetration. The "perfect storm" analysis, according to Finkel, et al., could have important implications for treating and preventing domestic violence-by lowering even one of the factors, incidents could be avoided (p. 545).

In 2018, Finkel and Hall changed their conceptualization and separated the $\mathrm{I}^{3}$ Model from Perfect Storm Theory. They described the $\mathrm{I}^{3}$ Model as a metatheory, "to serve as a general framework for guiding the development of interesting research questions and novel theorizing about the causes of behavior" (p. 127). Theories, on the other hand, "encompass sets of principles that can help to explain and predict observable phenomena... which help scholars develop falsifiable hypotheses" (p. 127). According to the Perfect Storm Theory, "an individual is especially likely to enact a given behavior 
in a given context when instigation and impellance are strong, and inhibition is weak" (p. 127). As it relates to domestic violence, the Perfect Storm Theory operates as delineated earlier in this section.

Difficulties have arisen in conceptualizing the constructs and in operationalizing them. For example, in one of the earlier studies, dispositional aggressiveness as a construct was operationalized as trait retaliation tendencies and trait aggressiveness, which theoretically predicted increased aggression as an impellor. But, Finkel and Hall (2018) posed the question: "how do we know that?" Could those traits actually reduce one's tendency to override his proclivity to aggress? (i.e., disinhibit) (p. 129). Similarly, other constructs, such as relationship commitment, which was predicted to reduce aggression by way of inhibition, might actually reduce the aggressive response to a partner's instigation due to the commitment itself, rather than through inhibition-and therefore act as a disimpellor.

Finkel and Hall opined that these unknowns are a reflection of what is not known generally in the field of aggression, rather than a limitation of the theory. They acknowledged that many risk factors likely increase aggression through more than one process. Finkel and Hall noted, for example, that the belief that aggression is an appropriate method for conflict resolution could foster aggression through both impellance and disinhibition. They concluded that what is needed is "strong evidence about the process or processes through which risk factors for aggressive behaviors exert their effects" (p.129). Even still, Finkel and Hall (2018) argued that the $I^{3}$ Model is an organizing framework for aggression risk factors due to its focus on the processes through which they influence aggression. As research progresses on the Perfect Storm 
theory using the $\mathrm{I}^{3}$ Model, scholars will need to agree on the operationalization of known risk factors.

\section{Bell \& Naugle (2008)}

In their review of domestic violence theories and limitations, Bell and Naugle (2008) recognized the need for more comprehensive theory and called for research that investigates proximal and contextual events related to domestic violence incidents, and that includes the perspectives of perpetrators as well as victims. Toward that end, Bell and Naugle developed a contextual framework that incorporates components of existing domestic violence theories and findings from studies related to those theories. In this study, Bell \& Naugle's intimate partner violence contextual framework is the organization by which findings are examined. The contextual framework is discussed more fully in the next chapter.

\section{Malle (2007) folk-conceptual theory of behavior explanation}

The investigator used this theory to understand participants' responses. Malle (2007) proposed a dual nature of explanations — which include the actor/explainer's underlying cognitive state related to a behavior explanation, such as beliefs, desires and intentions.

The second part of the dual nature of behavior explanation relates to the explainer's social purposes of behavior explanation, such as clarifying an act or event for another person, or for influencing another person's impression. Malle identified four types of explanation: (1) explanations stemming from the explainer's beliefs; (2) explanations stemming from the explainer's desires; (3) explanations indicating the 
explainer's intention for behavior; and (4) those explanations imputing the causes of unintentional behavior.

Furthermore, Malle (2007) proposed that there are linguistic forms that can reveal whether explainers are attempting to distance themselves from bad actions or to lessen culpability or otherwise avoid responsibility for their actions. To identify the types of explanations and whether any exculpatory linguistic forms were used by participants, provisional codes were created for Beliefs, Desires, Intentions, Causes and Exculpatory Linguistics. The investigator examined participants' linguistic forms and to understand responses that included exculpatory linguistics.

Among the emerging domestic violence theories, the intimate partner violence contextual network proposed by Bell and Naugle (2008) responds to the identified need for perspectives of batterers, including proximal precipitants and the context of discrete violent incidents. This theory is described in the next chapter and is the theory used to examine results of this study. 


\section{CHAPTER III: INTIMATE PARTNER VIOLENCE CONTEXTUAL FRAMEWORK}

Bell and Naugle (2008) reviewed existing domestic violence theories and their limitations. In the review, they identified a need for more comprehensive theory which takes into consideration the perspectives of both victims and perpetrators. In addition to the perspectives of victims and perpetrators, Bell \& Naugle (2008) recommended that future research should “...address contextual and proximal events associated with IPV [i.e., domestic violence] episodes" (p. 1101). With regard to the latter, Bell and Naugle (2008) proposed a contextual framework for conceptualizing domestic violence incidents (See Figure 2). The factors conceived as impacting violent incidents relate to the perpetrator of the violence.

\section{Arrangement of Factors in the Framework}

In the contextual framework factors are arranged in terms of:

Antecedents. This factor was conceived in two ways:

1. Distal/static antecedents are those events or stimuli that are related to the batterer's background, and may be indirectly related to violent behavior, such as childhood abuse and demographic features; they provide context; and

2. Proximal antecedents are considered to be precipitants of a particular violent episode and may be variable in their content, such as partner requests/demands and current/recent stressors.

Behavioral repertoire. This factor provides context and refers to deficits in adaptive skill sets to achieve desired outcomes and include deficits such as emotion 
regulation skills and communication/conflict resolution skills that can foster a batterer's use of violence.

Verbal rules. This factor provides context and is also known as beliefs and is hypothesized to influence violence by their endorsement of the use of violence to achieve desired outcomes and included are elements such as beliefs about relationships and beliefs about non-violent conflict resolution strategies. For example, an articulated belief that: "there are times when violence is the only way to resolve a conflict," theoretically could influence a batterer to engage in violence.

Discriminative stimuli. This factor is related to proximal events and refers to situations that, by their occurrence or presence indicate the likelihood or opportunity for the batterer to become violent, and includes elements such as presence of partner, location and presence/absence of others.

Motivating factors. This factor is related to proximal events and refers to situations that temporarily change the strength of perceived reinforcers or punishments to the batterer's use of violence and include elements such as drug/alcohol use, emotional distress, and relationship satisfaction.

These factors are all conceived as conditions which interact to enhance the likelihood of domestic violence incidents by the batterer. Another category, consequences, is conceptualized as having characteristics that are both precipitant of violence and also have features that are resultant of violence.

Consequences. In the network, consequences were conceived in two ways:

1. Consequences can be related to how violence can be instrumental to achieve a 
desired outcome, and include factors such as using violence to escape/avoid an argument and using violence to achieve partner compliance (precipitants);

2. Consequences can be related to results of using violence, such as partner leaves relationship and police involvement (resultants of violence).

(Bell \& Naugle, 2008, p. 1102-1103)

Bell and Naugle (2008) argued that the contextual framework integrates parts of existing domestic violence theories and also integrates the findings from studies related to those theories into one comprehensive framework.

In addition, they argued that the contextual framework is flexible enough to include future empirical findings. Bell and Naugle (2008) proposed that their contextual framework allows for investigation of various combinations of the factors in episodes of domestic violence, and that their contextual framework may assist in the improvement of batterer intervention programs.

Furthermore, Bell and Naugle suggested that by integrating concepts and empirical findings from various theories, the contextual framework may "help to bridge commonalities across IPV researchers and increase efforts for collaboration among IPV researchers from varying social science disciplines and theoretical orientations" ( $\mathrm{p}$. 1102).

The investigator examined proximal, contextual and historical events of domestic violence episodes identified by study participants to analyze their fit within the contextual framework proposed by Bell and Naugle (2008).

Scholars also have argued that research regarding the perspectives of domestic violence offenders may contribute to the understanding of how to effectively intervene in 
relationships affected by domestic violence (Flink \& Paavilainen, 2008; O’Leary \& Smith-Slep, 2006).

Thus, this study attempted to provide additional insight about the proximal, contextual and historical events associated with incidents of domestic violence from the perspective of the male offenders - as has been called for by domestic violence scholars (Anderson, Gillig, Sitaker, McCloskey, Malloy \& Grigsby, 2003; Flynn \& Graham, 2010). 
Figure 2. Bell \& Naugle Intimate Partner Violence Contextual Framework

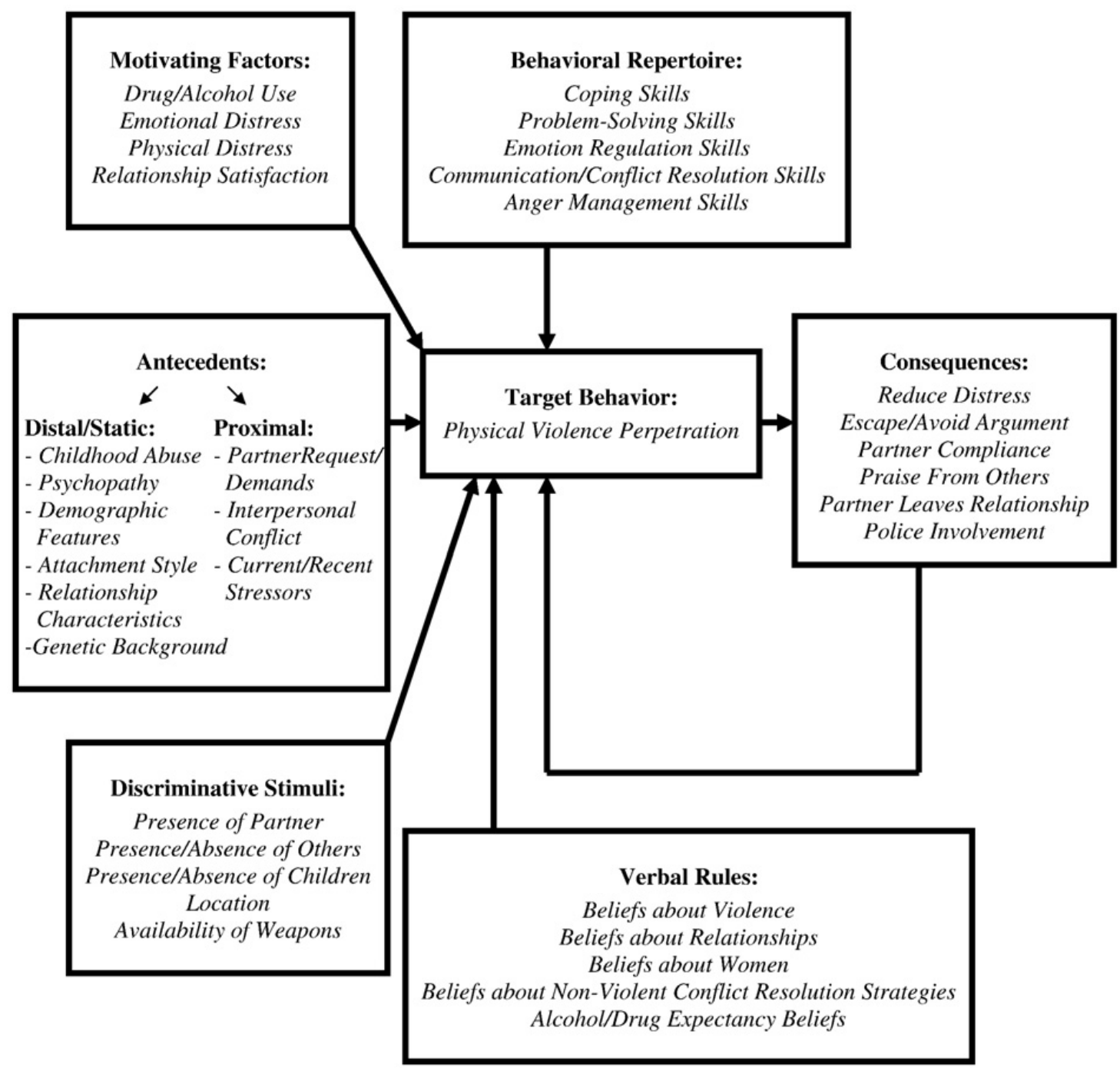

Bell \& Naugle, 2008

Reproduced with permission 


\section{CHAPTER IV: RESEARCH METHOD}

\section{Study Design}

This qualitative study consisted of in-depth individual interviews with men arrested or otherwise court ordered for domestic violence offenses against their female intimate partners. All participants were either in the process of registering to attend a BIP, or currently attending BIPs. Their specific paths to BIPs are detailed below in the sample discussion.

Qualitative research is intended to approach the area of interest in a realistic, nonlaboratory setting, to describe, understand, or explain social phenomenon through analyzing the experiences of individuals or groups or through analyzing documents that reflect experiences or interactions (Flick, Kvale, Angrosino \& Barbour, 2007).

Qualitative research methods are seen as a useful means for gaining insight into "social, emotional and experiential phenomena" (Jones, 1995, p.42).

Fenton \& Rathus (2009) endorsed the value of qualitative data collection for domestic violence scholarship, which in their research "revealed a wider range of men's descriptions of their violence than typically discussed in the literature" (p. 149) and recommended clinical approaches to "elicit the client's own statements of concern about their aggressive behavior," which may reduce defensiveness and improve BIP outcomes (p. 158). Qualitative research also is appropriate for eliciting subjective views, and for revealing how people represent themselves, and how people react to a situation in context (Flick, Kvale, Angrosino \& Barbour, 2007).

Qualitative research allows for people to describe their experiences so that details and complexities are captured, which can contribute to theory development through 
elaboration of the phenomenon and also through identification of themes (Kazdin, 2003). Domestic violence theory is still in an evolutionary phase. Since current theoretical models do not comprehensively account for domestic violence, and do not predict the circumstances under which it will occur, nor integrate contradictory findings, qualitative methods are appropriate for this area in which theoretical knowledge is incomplete (Babcock, Green \& Robie, 2004; Corvo, Dutton \& Chen, 2008; Feder, Wilson \& Austin, 2008; Flick, et al.,2007; Frye \& Karney, 2006; Smedslund, Dalsbø, Steiro, Winsvold, Clench-Aas, 2007).

\section{Securing the Sample}

\section{Study Site}

The Chief Executive Officer (CEO) of the Advocate Program agreed to allow this investigator to recruit study participants. The Advocate Program is the central intake office for people mandated to participate in batterer intervention programs in MiamiDade County. Advocate Program staff conduct intake interviews and provide a list of agencies that provide batterer intervention programs. The CEO consented for this investigator to recruit and to conduct interviews on the premises of the Advocate Program, located at 1399 N.W. $17^{\text {th }}$ Avenue, Miami, Florida. This organization was identified as a promising location for participant recruitment, because during calendar year 2013, the Unit saw over 2,700 clients for initial intake.

After several months of nearly fruitless recruitment efforts, the Advocate Program CEO suggested that the investigator try recruiting subjects at the Advocate Program's Court location. The Central Intake Unit process involved two-hour interviews with Advocate Program staff, after which prospective participants generally declined to 
participate in study interviews. On the other hand, persons at the Advocate Program Court location were subjected to a short registration process after they had been ordered by the court for BIP.

It was thought by the CEO that persons may be more inclined to participate in this study's interview after having engaged in the shorter registration process. Many persons were still disinclined to participate in the study. In general, recruitment was hampered by the need for English speakers due to this investigator's language limitation. In addition, offenders often were disgruntled after their court appearances and refused participation. Hence, both locations had drawbacks that delayed data collection. However, nine of the ten participants eventually were recruited at the court location.

Upon IRB approval of this second location, this interviewer secured an office for private interviews, and recruitment ensued twice a week — on days designated for domestic violence court.

\section{Study Locations}

The study was conducted in Miami-Dade County, Florida (Miami). According to the 2010 U.S. Census, Miami-Dade County, Florida, is the most populous county in the southeastern United States and the seventh largest in the nation by population. Palm Beach, Broward and Miami-Dade counties comprise the Miami-Fort LauderdalePompano Beach Metropolitan Statistical Area (MSA), the nation's eighth largest Metropolitan Statistical Area and fourth largest urbanized area, with a population of almost 5.7 million (Mackun, Wilson, Fischetti \& Goworowska, 2011). 


\section{Study Sample}

The investigator recruited a convenience sample of ten adult male domestic violence offenders over the age of eighteen. Criteria for inclusion in the study also included men (1) who were arrested for a domestic violence offense, or (2) for whom civil court restraining orders were issued because of domestic violence against their female partners; or (3) who have been court mandated to attend a BIP because of their court case dispositions of guilty or as a result of a plea bargain in criminal court or (4) whose cases were diverted from prosecution at the pre-trial status to attend a Batterers Intervention Program (BIP) in Miami-Dade County, Florida; and (4) who have presented at the Advocate Program premises for purposes of Intake, and who may or may not have yet participated in a Batterer Intervention Program; and (5) who speak English fluently.

Five of the participants had been arrested for domestic violence offenses; two participants were court mandated to attend a BIP because civil restraining orders were entered against them; and three of the participants had cases that were diverted from prosecution at pre-trial to attend BIPs.

English fluency was a requirement primarily because the investigator, who also served as the interviewer, does not speak Spanish or Creole. This did not preclude having Latinos in the study, however. But, because his study relied upon verbal reports of highly sensitive subject matter, including nuanced communication, fluency in English was required as opposed to speaking English "very well" or "well." Participants were provided with information about the study and they provided informed consents to participate; the content of which was approved by Florida International University's Institutional Review Board. 
Ultimately, a sample of ten subjects was recruited to the study. Demographics of the sample will be discussed in the following chapter.

\section{Data Collection Procedures}

\section{Human Subjects}

The study was submitted for human subjects review by Florida International University's Institutional Review Board (IRB). Human Subjects Research Curriculum was successfully completed by this researcher as well as the Responsible Conduct of Research Curriculum.

To ensure anonymity of the data, participants in the study were asked to choose an alias by which their data were identified. The data collected contain no personally identifiable information. Participants were not asked to provide their actual names, nor were they asked for birthdates, social security numbers or other identifiable information. Completed data forms, audio recordings and transcriptions were maintained in a locked cabinet at FIU for safekeeping, and only the investigator and her dissertation chairperson have access to the cabinet.

The interview schedule used in the study involved asking the participant to recall and recite an incident of domestic violence for which he was arrested, or otherwise court referred to participate in a BIP. Such recollection could be disturbing to the participant and could revive negative emotions. Therefore, a licensed mental health professionalwho was not the investigator-was available to each participant after the interview-or, if participant a decided to withdraw — to provide emotional support, assist with processing feelings and deescalating aggression. In this study, one participant terminated the interview early after reciting his perspective of the violent incident and what 
precipitated the violence. The participant had recently bonded out of jail after a weeklong incarceration and expressed feeling emotionally distressed after his seven-minute recitation of events; however, the participant declined professional supportive assistance and departed with a friend.

\section{Interviewer}

Interviews were conducted by the investigator. The investigator is a Licensed Clinical Social Worker (LCSW; FL) and has over eighteen years of experience in the field. In addition, she received formal training by Dr. Beaulaurier in qualitative research interviewing. Dr. Beaulaurier has trained numerous researchers in qualitative interviewing techniques. He has served as the principle methodologist on several large investigations, including those funded by the National Institutes of Health, National Institute of Justice, the John A. Hartford Foundation and the Substance Abuse and Mental Health Services Administration (SAMHSA) of the U.S. Department of Health and Human Services.

Participants were informed that the researcher is a LCSW, and that she has a professional responsibility to report imminent harm to the participant in situations of suicidal intent, or intent to harm to others. Because of the anonymity of the participants, the process for disclosure of imminent harm of suicide or intent to harm others was: the interview would be terminated and the researcher would take steps to ensure participant's safety and the safety of others, including calling the police if that should become necessary. This issue did not arise in any of the interviews. 


\section{Interview Procedures}

Semi-structured face-to-face interviews were conducted with eligible participants in a private room at the Advocate Program. At the beginning of each interview, the details and the purpose of the study, as well as potential risks of participating in the study and how to withdraw from the study were explained verbally to each participant, including his right to withdraw from the study at any time during the interview process, and the researcher's mandatory obligation to disclose suicidal intent or intent to harm others.

Participants were also advised that no Advocate Program staff would be aware of whether they participated in the study, and that there were no negative ramifications of non-participation. Time was provided for the participants to ask questions and receive clarifications.

Each participant was asked to select an alias identifier for purposes of the study. A written copy of the above information (Informed Consent) was offered to each participant, and each participant was asked to sign using his selected alias on another Informed Consent copy, which was retained by the investigator (Appendix A).

The Advocate Program Domestic Violence Intake Unit staff and Court Registration Unit staff do not have access to the interview recordings or transcripts, nor to the identities of those who participated in the study, and all participants were informed of these facts orally and in the written Informed Consent.

Interviews took between 7 and 57 minutes, including the interview that was terminated early. The median length of the interviews was 28 minutes. In the first part of the data collection, participants were asked to respond to a Demographic Information 
Sheet consisting of eleven questions. The questions are fully described below, and the Demographic Information Sheet is attached as Appendix B. Participants were provided with the option to have the questions read to them and respond verbally, or to respond to the questionnaires by reading and writing their responses themselves. All participants elected to have the questions read to them and responded orally. Participant aliases were used on all interview materials to protect the identity of participants.

Interviews were digitally recorded, guided by an Interview Schedule, described below, and transcribed verbatim. Digital recordings and transcripts were maintained in a securely locked file cabinet in a locked office at the university, or in a password-secured electronic file within the researcher's locked office and are accessible only by the investigator, and her dissertation chair. The interviews were transcribed by the investigator. There is no personally identifiable information on any of the data collection materials or recordings or transcripts, since participants used aliases.

Participants received a $\$ 20$ gift card for compensation. The process for participants who initially agreed, but later changed their minds was: Any participant who, at the time of the interview, declines to be recorded or decides to withdraw from the study will be paid for his participation and excused from further participation. As previously stated, one participant withdrew from the study after seven minutes, and after he had described the context of the incident, and the proximal precipitant of the violence. He was provided with a $\$ 20$ gift card as compensation. 


\section{Assessment Measures}

\section{Interview Schedule - Appendix C}

An interview schedule added focus to the interviews, and provided an opportunity for the interviewer to explore: the immediate context of the domestic violence incident for which the participant was arrested; the conditions or other events during the hours preceding the domestic violence incident; relevant past experiences - such as frequency of conflict, managing conflict in general, family-of-origin conflict management styles; and difficult childhood/adolescent experiences with peers and authority figures.

The interview schedule was developed based on the literature review, identified gaps in knowledge, and the focus of study. For example, one focus of interviews was on areas related to causal attribution to violent episodes as previously discussed (Flynn \& Graham, 2010).

In addition, perspectives of severity of violence were explored in terms of familyonly violence or generalized violent behavior. Persons who engage in family-only violence have been identified as the least violent among the subsets of batterers, and their problems have been reported to be related to insecure attachment patterns and mild deficits in social skills (Holtzworth-Munroe, Stuart, Meehan, Herron \& Rehman, 2003; Stith, Rosen, McCollum, \& Thomsen, 2004).

Distal attributes were explored to take into consideration research that indicated a relationship exists between adolescent emotional and behavioral problems and later perpetration of domestic violence (Ehrensaft, Moffitt, Caspi, 2004). Similarly, domestic violence in the participant's family of origin was explored as relevant to domestic 
violence perpetration in later years (Ehrensaft, Cohen, Brown, Smailes, Chen, \& Johnson, 2003; Olsen, Parra, \& Bennett, 2010).

Overall, Forgey, Badger \& Krause (2011) identified three areas associated with risk of domestic violence perpetration, which areas are reminiscent of Bronfenbrenner's ecological systems theory (1999). These risk-factor areas generally represent the areas of inquiry to be addressed in the interviews: (1) socio/cultural/environmental; (2) individual biological and psychological; and (3) family/ relationship (Forgey, Badger \& Krause, 2011, p. 329). In addition, factors identified in the contextual framework for domestic violence incidents developed by Bell \& Naugle (2008) informed development of the interview schedule.

A demographic data sheet was also used. Items include questions related to age, ethnicity, race, education, occupation, employment status, and marital/relationship status.

\section{Data Analysis}

Interviews were recorded into a digital audio format and transferred from the recorder as an audio file to a laptop computer for transcription. The transcription was assisted by using Express Scribe transcription software. All interviews were transcribed verbatim.

Post interview field notes were made after each interview to capture details about the environment, participant's demeanor, and any unusual occurrences during the interview which may impact the participant's responses.

ATLAS.ti Qualitative Analysis and Research software (“ATLAS.ti”) was used to organize and assist in the analysis of transcripts of the interviews. Transcripts were uploaded in ATLAS.ti and coding began as interviews were completed and transcribed. 
The software was also used to aid in coding and classifying and creating memos. Codes consisted of a word or short phrase that captured the principal content.

\section{Free Codes}

Transcripts were analyzed primarily by use of open coding techniques. However, before beginning the open coding process, a list of codes based on concepts in the literature was generated. These codes, that are not initially linked to text are called "free codes" in Atlas.ti. Most free codes were associated with the concepts in Bell and Naugle's (2008) domestic violence contextual framework (Figure 1) and with the concepts in Malle's (2007) folk-conceptual theory of behavior explanation. These a priori codes were considered provisional until they were "grounded" by being attached to relevant quotations in the transcripts. Any code that was created prior to open coding was retained for analysis only if it was linked with a passage of text, or if it was linked with another code that was linked to text (Muhr, 2003-2005; Strauss \& Corbin, 1990). The a priori codes that could not be linked to actual quotations from respondents were dropped.

\section{The Open Coding Process}

The investigator followed the recommendation to "code liberally;" to capture as many different concepts and categories of responses as possible. Liberal coding is a process by which the investigator reads the transcript multiple times seeking to identify as many concepts that emerge from the text as possible (Ford, Oberski \& Higgins, 2000). As the analysis progressed, codes and categories were reviewed to eliminate redundancy, and to confirm fidelity with basic coding strategies. Codes with redundant concepts were merged. In addition, quotes themselves that were linked to specific codes were reviewed 
and reconsidered for accuracy and consistency (Ford, et al., 2000). Both the codes that were created through the open coding process and free codes were attached to passages of text during open coding.

\section{Constant Comparison and Negative Case Analysis.}

The investigator used the constant comparison method throughout the open coding process (Dye, Schatz, Rosenberg \& Coleman, 2000; Padgett, 1998). Transcripts were repeatedly reviewed for evidence of codes and categories that emerged in later phases of analysis, and to ensure that codes were used uniformly throughout the analysis. Negative case analysis was used to verify main findings. In negative case analysis, the investigator examined the data for any statements that served to contradict important findings to increase internal validity and to reduce investigator bias (Padgett, 1998). This review and refining process sometimes resulted in quotes being unlinked from codes or new codes being created to reflect new shades of meaning. Additionally, some codes that had emerged in later phases of analysis were assigned to content from interviews analyzed earlier; thereby ensuring coding consistency.

\section{Theoretical memos}

Comments and notes of theoretical importance were kept throughout the analysis in the form of memos in the Atlas.ti software (Strauss \& Corbin, 1990). The memos were linked to codes and quotations (MacGowan \& Beaulaurier, 2005). The memos provided a guide for subsequent analyses of the data, as well as leaving an "audit trail" of decisions and salient events in the transcripts (Drisko, 1997; Padgett, 1998).

\section{Themes and Theory Development}

Transcripts were coded to the point of saturation; that is, until no new or unique 
codes emerged. Once this point was reached, the investigator explored the relationships between codes and the emergence of more abstract higher order concepts and codes. In this phase the investigator identified themes, created higher order codes, and explored hypothetical relations between codes (Strauss \& Corbin, 1990). This process was aided by using the network function in Atlas.ti to create relationship maps. Relationship maps have the advantage of allowing the investigator to follow hypothetical and deductive relationships back to the grounded codes that emerged from open coding - that is, to the participants' quotations to which they are attached (Macgowan \& Beaulaurier, 2005). Thus, even the most complex concepts were linked to the participants' own words. The data's central themes, major codes, core concepts, and their patterns and relationships were explored through this process (Barry, 1998; Miles \& Huberman, 1994;

Weitzman,1999). 


\section{CHAPTER V: RESULTS}

The sample consisted of ten men who had been court ordered to community Batterer Intervention Programs in Miami-Dade County, Florida, for perpetration of domestic violence against their female partners.

Participants chose pseudonyms in lieu of their legal names. Two participants chose the same name, "Kevin." To differentiate them, they are identified in this study as Kevin1 and Kevin2.

\section{Demographic Information}

Seven participants were African American. One participant indicated that he was born in Guyana but adopted at age three by U.S. citizens and was raised in the United States. Two participants identified as Hispanic; one whose father is from Spain and the other participant identified as Cuban American. All participants were between 19 and 45 years of age. Half were below 30 years of age. Five of the ten participants graduated high school. None of the participants were college graduates, although three had some post-secondary education.

Four participants responded that they were unemployed, and one participant identified as a college student. The remaining five participants responded that their annual incomes were severally: $\$ 2,400, \$ 13,000, \$ 24,000, \$ 39,000$ and $\$ 70,000$. The participant who identified his annual income as $\$ 39,000$ reported that he had lost that job due to incarceration related to the domestic violence offense and was currently starting a handyman business; his current income is unknown. The participant who initially 
identified his annual income as $\$ 70,000$ later referred to working at the "labor pool"1 during his interview. In addition to the participant who was a college student, another participant was studying automotive repair, all others were in low wage positions. ${ }^{2}$ See

\section{Table 1}

Eight of the ten participants described domestic violence incidents that fit the type of violence described as Situational Violence; that is, there was no indication of Coercive Controlling (Intimate Terrorism) tactics by them. Not enough information exists to characterize the remaining two participants who had arrest records for offenses unrelated to domestic violence. Because the incidents for which they were mandated to BIPs occurred after their female partners had ended the relationships, the violence is conceivably classified as Separation Instigated Violence.

\footnotetext{
${ }^{1}$ Labor pool refers to both location and type of work. Locations are informal (such as Home Depot) and formal (temporary employment agencies) where people are hired on a daily or hourly basis for unskilled or skilled jobs.

${ }^{2}$ Occupations were variously identified as landscaper, cook, security officer, waste management, handyman, hurricane relief survey, warehouse work.
} 


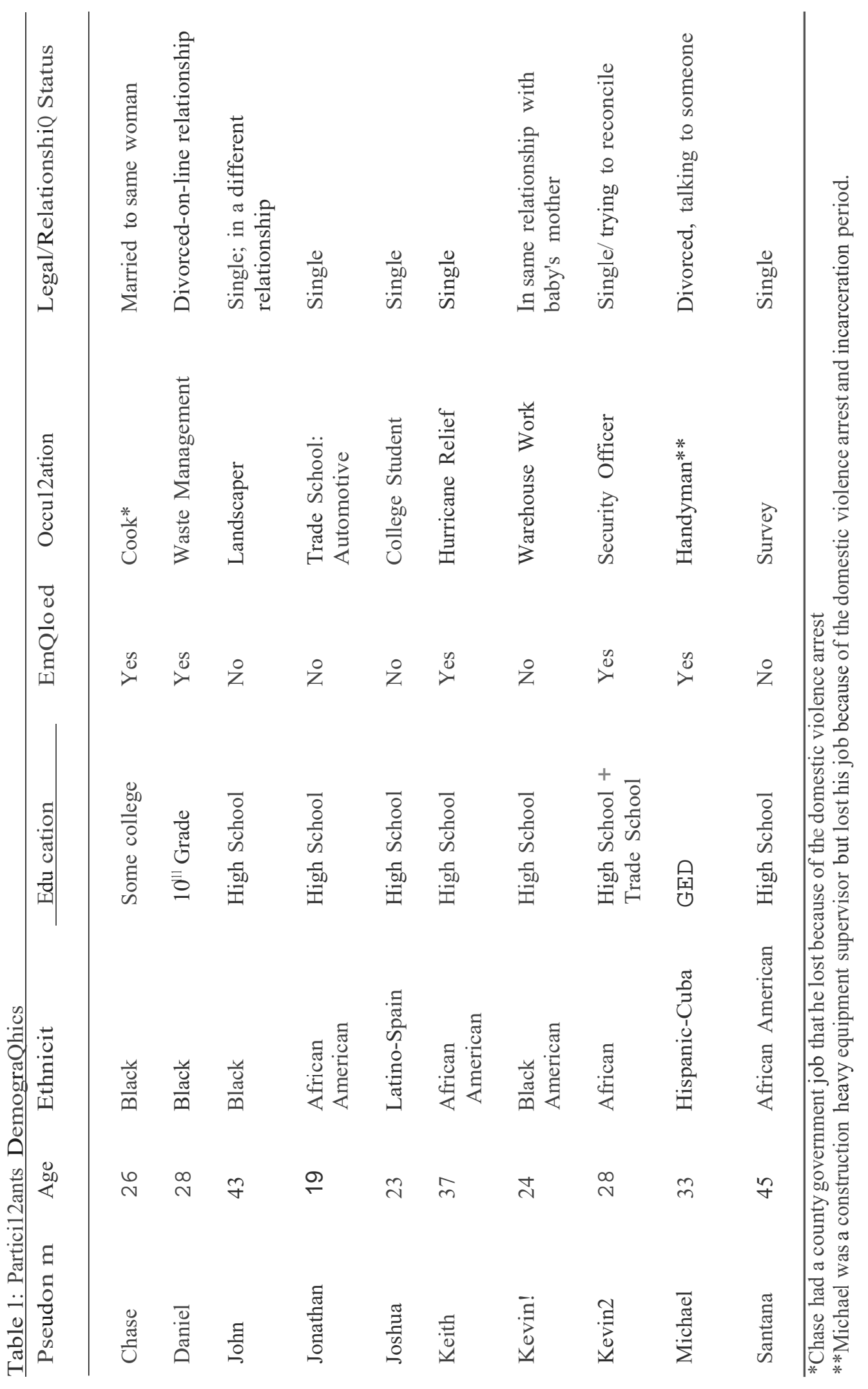




\section{Distal Contextual Findings}

Childhood trauma. Traumatic distal contextual experiences were often described at length by participants, including those that related to their female partners.

Three participants disclosed experiencing childhood abuse. Two of the same three participants also acknowledged having witnessed domestic violence between their parents.

One participant, whose pseudonym is Chase, reported that he experienced child abuse, "...my mom, she used to drink a lot...when I was younger, she used to lash out..."

Kevin1 reported that he was abused by his much older sister, “... she used to beat me up..."

Joshua, one of three children in his family and the only male child, did not directly identify experiencing child abuse. He reported that his father was "harder" on him, and that his older sister would "beat me up."

Joshua: ...but when I grew up, it was harder on me. I would understand; I mean, I wouldn't want him [father] to be as aggressive with my sisters. Because my dad, we have gotten into some scuffles... [Sister] Paula was 8 years older. Paula would beat me up like a big brother. She would bash my head into the floor, stuff like that.

Chase and Kevin1, who reported experiencing child abuse, also reported witnessing domestic violence against their mothers.

Chase: I took that for two years [physical abuse from his wife] before I ever put my hands on her. Because, I saw that growing up...mom's husband used to get drunk...she never hit back. But it finally took, you know the breaking point... I remember that - being that little kid and standing in front of my mom-like you not hitting her no more... and then we never saw him again.

Kevin1: ...I didn't really have a father...I knew who he was...he used to beat on my mom. After my father, I knew two of my mother's boyfriends. One was nice and the last one - the same like my father. 
Jonathan, a participant who did not report experiencing child abuse reported that his mother was "in a lot of abusive relationships." He reported that he was removed from his mother's care by the Department of Children and Families and placed in a group home, and that his father was in jail for murder. Jonathan further reported that he was in a "lot of fights at school."

Jonathan ...I was keeping getting kicked out of school for fighting...they sent me to Opportunity school...they finally sent me to Juvenile program.

Jonathan ...my mom had gotten into it with one of my sisters, so I had to go to DCF...now, they pay for mostly everything for me - they just paid to get me moved in... ${ }^{3}$

Other participants reported distal factors that provide background context to the trauma in their lives.

Daniel reported that he has a twin sister, and that they got adopted:

Daniel: ...there were four of us...the other two had different dad...we all had the same mom... we wasn't staying with our mom. My dad passed when I was two...We got adopted. In 2009, we finally met our mom...the people were saying that she was more into clubbing - she kept staying out, she got caught up in all that.

Daniel reported that the four siblings were adopted by a family who had their own

children and when he and his sister were young teenagers, the family returned them to the Department of Children and Families.

Daniel: ...I guess they felt like we were too much to handle, so they said they were going to send us to a program...we thought we was all going to the same program...[but] what she did was drive and one by one, stop at one place [and then another] and gave each an envelope and said, "here's where you get out."

\footnotetext{
${ }^{3}$ When foster children are in the care of the Department of Children and Families and they reach 18 years of age, they are considered "aged-out," and are entitled to "Extended Foster Care," which includes extended benefits until age 21 to help them become independent. For example, assistance is provided with postsecondary education, job training, housing, a monthly stipend, among other benefits. (Reg. 65C-41, Rulemaking Authority 39.012, 39.0121 FS).
} 
She didn't even get out [of the car] ... and we started getting emotional... and then I see my sister crying...

Daniel reported that he and his siblings eventually were placed in foster care with different foster families.

Chase reported that he and his wife have four children; including one toddler who died, and two other children who suffer from the same serious seizure disorder as their two-year old son who died.

Chase: ...I stopped to play ball to clear my mind, because, we have four kids together...I have two special needs kids...my daughter, she doesn't stay still cause of epilepsy, and my son too...My kids...there's my stepson...I have fourthree actually. I had a two-year old son that we lost...epilepsy.

This context was both the distal backdrop for the conflict between Chase and his wife, and it was also the proximal context for the domestic violence incident:

Chase: ...I say, "when I go to the [basketball] court for a couple hours, it clear my mind up." So she say, "No, come home and help me."

Chase reported that his wife is home all day with his young children, including the two children with epilepsy, and she was angry because Chase did not go home immediately after work to help her with the children. Chase reported that his wife has a history of hitting him:

Chase: ... One thing I can say, once he passed [their 2-year old son], it got worse - she started attacking...I'm like [her] personal punching bag.

Kevin 2 reported distal contextual trauma experiences as follows:

Kevin 2: I was adopted when I was three ... I was told that my parents died in Africa and I was in an orphanage... My parents worked for Pan American Airways and my [adoptive] mom retired when they went bankrupt...she ended up adopting five different kids...I am the second oldest...I don't speak to them anymore because I shamed them with being with the woman I am with now... because she is from poverty...I let her [his mother] down as far as having a child early and not having stability myself and being able to take care of my 
family...My mother was kinda racist... she was really tough on me. I felt like I was the child she was always toughest on...I'm the only one who still lives in Miami...we traveled a lot...I think my adoptive mom lives in Costa Rica. They bought a house there.

Kevin 2 also reported that he received a football scholarship to Ohio State, but an injury ruined his career plans:

Kevin 2: I lost it because I got injured. I had a fracture on my rotator cuff and ...I had to have reconstructive surgery...I have a metal rod in my shoulder...so ...they just sent me home...they said change your path in life. My dream was really go to the military after football...get my education and go straight to the military, become an officer. I can't even join the military. So, it destroyed a lot of dreams that I had.

A more recent contextual traumatic experience- but not proximal context that precipitated the violence-was Kevin 2's report that in the recent past, he was threatened at gunpoint when working as a tow truck driver and thereafter suffered from extreme anxiety. As a result, Kevin 2 reported that he had taken lower paying jobs which created substantial financial stress. Kevin 2 indicated that the income decline resulted in relocating to a motel and placing their toddler son with the maternal grandmother.

Furthermore, Kevin 2 reported that an underlying issue was resurrected during the incident:

Kevin 2: I felt the entire time she was pushing me away was because she wanted to leave me because our first child is not mine....and I don't know and I still don't know...I started thinking in the back of my mind... [that] she needed to push me away so that I wouldn't later question or find out...in the back of my mind it was always hurting me...

\section{Contextual Factors About Female Partners Reported by Participants}

Seven participants reported distal contextual conditions and trauma related to their female partners, or behaviors of their female partners that they believe contributed to the violence. 
Jonathan described threats made by his fiancé:

Jonathan: She told me herself that the only way you getting out of the relationship is that you go to jail or something happen to you. She kept tellin' me that. And that's what she did. But, I didn't want to think she would do all those things.

Jonathan described what his fiancé did to his residence while he was in jail:

Jonathan: I went back to my house and my whole house was way worse... she left the refrigerator with old meat, turned on my oven and she put a bag on top of the stove to try to set it on fire, but she turned on the wrong part. I went inside the room, she had cut up my whole bed, she wrote curse words all over the dresser, broke the mirror on the dresser, the bathroom and room door, she broke the curtains - every last piece of clothes I had, she poured bleach on them and eggs.

Jonathan also reported that his fiancé had a conflictual relationship with her

mother and that she had been involuntarily hospitalized according to the Florida Baker Act ${ }^{4}$ "a couple times."

Jonathan: ...her mom got her Baker Acted a couple times...she's very smart, cause she has a high GPA, but it's really how her mom treats her-it falls back on me... she make all the anger come out on me and then I have to deal with it...

Chase reported that his wife witnessed violence against her mother and that his

wife's former husband was violent with her. Chase reported that he believed her past experience influenced her use of violence toward him:

Chase: ...her mom's husband...He hit her mom and he still does...her [motherin-law's] husband ain't nothin' but a monster.

Chase: .... lot of women, when they get used to being with someone aggressive and hitting, and then with the next guy, they looking for that, and then they hit you...

\footnotetext{
${ }^{4}$ The Florida Mental Health Act of 1971, FL Statutes Chapter 394, Section 467, allows for involuntary inpatient placement for treatment if a court finds that upon clear and convincing evidence, a person is at imminent risk of harm to self or another and has refused voluntary placement, or is incapable of deciding whether inpatient placement is necessary, or person is incapable of surviving alone or refuses to care for self and without such care and there is a real and present threat of substantial harm to person's well-being. http://www.leg.state.fl.us/Statutes/index.cfm?App_mode=Display_Statute\&Search_String $=\& U R L=0300$ $\underline{0399 / 0394 / \text { Sections/0394.467.html }}$
} 
John described his opinion about his former girlfriend:

John: ...she always wanted to be right She made no mistakes...it was just that she had too many personalities. Everyday was a rough day with her...

Joshua described his girlfriend's distal contextual challenges:

Joshua: she had trust issues...accusations...checked my phone... she had issues. She was sexually molested from $7-10$ years old ...by a grown man in the neighborhood... and she never told anyone....her father was a deadbeat [artist] painter - gone for at least half of her life...her dad never owned up to being her dad because he's Cuban and the kids are very white. She changed her name to her father's last name... he didn't consider her to be Latin because she doesn't speak Spanish like him...she had a troubled upbringing. She loved and hated her mom very intensely.

Michael reported that the incident occurred while they were on vacation and was related to the way his wife behaves when she drinks alcohol:

Michael: ... She's bi-polar. When she drinks, she turns into Dr. Jekyll and Mr. Hyde.

Kevin1 reported contextual factors about his fiancé's relationships with her parents:

Kevin1: Her dad don't want to have anything to do with her because she didn't finish school...

Kevin1 reported that his fiancé does not get help from her mother:

Kevin1: ...even though she's staying with them, they don't do anything to help out...in April, her mom want her and the baby out.

Kevin 1reported that his fiancé engaged in behaviors that bothered him and that he asked her not to do:

Kevin1: ...I told her I don't like to be grabbed; it don't feel right. And she kept doing it.

Daniel described an unusual situation wherein different family members variously convinced his wife to live with them, including: (1) her grandmother, (2) Daniel's step- 
mother, and (3) her father after he was released from prison. Daniel reported that his wife was easily manipulated, “it's like they was tryin' to get me out of the picture...[she] is my wife...They know that she's easily manipulated..." Daniel reported that later he learned that his wife was receiving a disability check, which he believed was related to the family members' competition for control of his wife.

Daniel reported that his wife sometimes engaged in behavior that he did not understand.

Daniel: When she gets mad, she starts cutting up her clothes. She did that one time when I took her to this supermarket and she started cutting up her pants...I had to cut it evenly to make it look right. She would even scratch herself sometimes and I would say, "What are you doing? You're hurting yourself...don't do that. Why are you hurting yourself?" Another time...she snatched [off] her bra. I say, "we got to go get you a bra cause you can't walk around like this; people were looking and watching...so, we get to the store and she end up making a scene and just dropped to the floor... and the security they came and they say, "hey what you doin?"...then she put her ring in her mouth and I tried to open her mouth...I took it because I didn't know if she was trying to swallow it or do something crazy.

Daniel reported that his step-mother's efforts to control his wife eventually led to accusations that he was violent and caused his wife to miscarry a pregnancy. Daniel reported that the disposition of the case was that he agreed to a Batterer Intervention Program, and "if I comply, they could dismiss it and everything be back to normal."

Daniel: ...we almost had children...I don't know what happened, because it was three times and she just kept losing the baby. I took her to my step-mother's the next time she was pregnant because at her family house there was about nineteen people staying there and sometimes she was hungry...I asked, "why didn't you tell me? I would bring you to my step-mother's or bring you some food; so then I took her to the hospital.

Daniel: ...I think there's something wrong with her, but when I first met her she didn't tell me all that. I was like, "why didn't you tell me?" and she was like, "cause I didn't want you to make fun of me." Cause when I took her to the hospital for the pregnancy, the doctor pulled me to the side and was like, "is 
she...do she... asking me a lot of questions, like "is she slow?" or "what kind of disability do she have?" But when I tried to ask her, she start telling me a little bit, trying to remember what she had...I just know that sometimes when she speak, she try to get the words out, but she talk fine most times...

Daniel reported that his step-mother helped his wife file for divorce and that he later learned from a relative that his ex-wife was with his step-mother's son:

Daniel: ...her son just got outta jail...and when I run into one of her daughters, she told me that the step-mom not even getting the money no more-it's her son. ....all along I was right. They was basically trying to get me out of the picture in the first place. So they went to get the Stay Away Order, they had to tell lies... at first I was still worrying [about his wife] ...mainly, I was just trying to make sure she's alright...I cried sometimes ...but, I'm glad everything went that way...everything happen for a reason.

\section{Precipitating Events}

In addition to the distal contextual events reported earlier, participants reported events that precipitated the domestic violence incidents.

Jonathan reported that his fiancé was mad at him because, "she said I spend more time with my friends than I do with her." Jonathan said his fiancé was packing to move and she left:

Jonathan: She came back...I was on the phone with my baby's mother. She don't like it when I talk to my baby's mother.

Michael explained that the incident occurred at the hotel pool during a weekend vacation:

Michael: ...we were sitting by the pool and we were having a couple cocktails; my wife starts getting violent and argumentative with a bunch of people so I grabbed her by her arm and I pulled her into our room because she was being very violent. And she ran to the front desk...

Santana believed that he was in an exclusive relationship with a young lady:

Santana: ... she kept me blind to these other two guys who liked her and I didn't know anything about it. When I did find out about it, she just told me, "we are 
friends"...Well, I got mad a couple times, I got mad about the guys—but I didn't get mad enough to go hurt her or violate my probation-nothing like that.

Kevin 2 indicated that he had doubts about whether he is the father of their first child and that his fiancé's behavior on the morning of the incident raised concerns about her current faithfulness:

Kevin 2: I come in after I had worked midnights... and I was tired and I laid down next to her and a couple hours later she was up and about — not a hair out of place, ready to go. She said she needed to drop some things off for our baby-and I said, well I want to go - can you hold on a moment. and she was rushing to go...I felt like she was pushing me away...Is there something you're hiding? Who were you going to see?

Chase reported that his wife was angry because he stopped to play basketball after work rather than going home to help with their four children, two of whom had special needs:

Chase: It was just a lot of arguing and screaming and you know, she slapped me. So, I was like ok, don't slap me no more. So, she slapped me again, so that's why I struck her back. So, that's when it got outta hand ...

John described the incident with his ex-girlfriend who approached him while he was playing dominos and started an argument.

John: ... I said, "Man, I ain't got time for this shit" and I walked away. And she called me back and I turned around and she threw something in my face... it was a cup of stuff she had made up; she threw it all in my face, my eyes was burning and stuff... and I reached through the car window and grabbed her, I didn't hit her or nothing - I just grabbed her.

Keith reported that his ex-girlfriend — who had been violent toward him during their relationship — was stalking him and that she approached him when he was at a pool hall with the young woman he was currently dating.

Keith: ... I grabbed the girl's hand and we walked out and [ex-girlfriend] followed behind us and she tried to run up, I guess to get physical with me and the girl as we were leaving and I gave her a shove in the face... 
Joshua described contacting his ex-girlfriend after the Injunction for Protection Against Repeat Violence (restraining order) expired, which reportedly led to another stalking charge against him.

Joshua: ... she stopped talking to me and I respected that - I reach out for once, it's been like a year, and I guess I just should have respected it - but I kept on calling back - and then I left messages and I started telling her like, you're a coward and why won't you talk to me, like this is stupid, you're like-I just said mean stuff ...I wanted to call her and see how she was doing and just settle everything and clear up.

Kevin1 reported that his pregnant fiancé was living with her sister and he was standing at the door during an argument.

Kevin1: ... we had gotten into an argument and she wanted me to come inside [her sister's] home, and knowing that her sister and her mom don't like me, I kept telling her I don't want to go in. She got mad, started grabbing me, pulled my jacket...I got really upset, I pushed her, which I regret...I pushed her down.

The precipitating event for the domestic violence charge against Daniel is unclear. He reported that his step-mother was involved in false accusations against him.

\section{Emergent Themes}

In their narrations of the violent incidents, participants raised certain issues frequently enough that notable themes emerged. Aside from the distal traumatic experiences, three other themes emerged that merit attention: (1) Adverse financial impacts, (2) Female Partner Aggression and (3) Poor Insight/Perceptions of Bias. These themes are described below.

Adverse Financial Impacts. The domestic violence arrests resulted in loss of employment for all seven participants who were previously employed. Among the three participants who reported being unemployed before their arrests, one was a college 
student, one worked odd jobs from a labor pool, and the other was enrolled in a Florida Department of Children and Families job training program.

As reported by participants in demographics information collection, eight of the ten participants are economically disadvantaged. In addition to their existing financial hardships, loss of employment created further adversity.

Florida law has special provisions for domestic violence arrests, which process delays bond consideration for those arrested for such offenses. ${ }^{5}$ Delays during the incarceration period can result in offenders losing their jobs and in addition, their arrest records can place them at a disadvantage for future employment because some employers require background checks.

Five of the ten participants reported that they had never been arrested before their arrests for domestic violence charges.

Three participants described particularly negative financial effects resulting from the domestic violence arrests. One respondent reported that because he was changing departments in his government job, a background check was conducted, as is policy.

Chase: ... I had a good job at the time. ...that same week, I was switching departments...I was getting a good raise. It was like a $\$ 6.00 /$ hour raise...so, when I was switching departments that same week, they checked it.

\footnotetext{
${ }^{5}$ Florida law (Statute 741.2901(3) requires that in cases of domestic violence, the State Attorney's Office must conduct a thorough investigation of the defendant's arrest history and the defendant must be held in custody until the background investigation is complete and then he or she must appear before a judge for a bond consideration. The State Attorney's Office investigation must include all previous arrests, any prior injunctions for protection (restraining orders), including history of other victims, and prior walk-in domestic violence complaints against defendants. In addition, when determining bail, judges must take into consideration the safety of the victim, the victim's children, and any other person who may be in danger if the defendant is released.
} 
Because of the domestic violence arrest and the required length of time in custody ${ }^{6}$, Chase reported that he lost his job Chase reported that he is currently working as a cook, and that:

Chase: “...ever since that day I work jobs and I get paid and I been cheated..." He reported that he struggles with resentment toward his wife:

Chase: ... you made me lose my job... Sometimes I get mad and ...sometimes I feel cheated because of the stuff I want to buy for my kids and I always think, "what would I be buyin', what would I be doin' right now if I had that job?" So, she feels like, oh, I can't be bringin that up again - if I've forgiven [her], I can't, you know, keep bringin it up: “Oh, you made me lose my job.” But, it comes up; it comes up.

Another participant whose financial situation deteriorated substantially because he was arrested relates to events that reportedly occurred while he was still in jail.

Jonathan: “...I had to go to DCF, so now they pay for mostly everything for me."

Jonathan reported that he had been in foster care for part of his childhood through the age of eighteen and as an aged-out foster child, Florida Department of Children and Families (DCF) provided financial support through the Extended Foster Care program to help him achieve independence.

Jonathan reported that after his arrest, while he was in jail for three days, his exfiancé entered the house and caused substantial damage. He reported that after he got out of jail, his landlord told him that he had one week to vacate the house, so he returned to his mother's home. In addition, Jonathan reportedly owed $\$ 400$ over and above the security deposit and last month's rent to pay for the damages. Among the benefits

\footnotetext{
${ }^{6}$ Florida law (n. 3)
} 
provided by the Extended Foster Care program is the provision of first and last month rent and security deposit. Jonathan reported that he does not expect to have the housing benefit ${ }^{7}$ again because the program requires that he leave the premises in the same condition as when he arrived.

Jonathan: "...everything gotta be ok for them to be able to do it again for you."

Jonathan indicated that he was unemployed, reportedly because his girlfriend "wrecked" his car that he used for Uber ride-sharing income. The domestic violence incident, as reported by Jonathan, resulted in substantial indebtedness and has potentially permanently negatively impacted his ability to have financial help from DCF for housing again.

Kevin1 reportedly was arrested for domestic violence and took a drug test as part of the process, the results of which were positive for marijuana. Therefore, Kevin1 was mandated to a Batterers Intervention Program and a substance abuse program. Kevin1 indicated that he could not afford the two programs and requested that his public defender negotiate for probation, which was reportedly denied by the state attorney.

Kevin1 indicated that he thought he got "a waive" for the programs, but he was re-enrolled after a year because he did not attend the programs. Kevin1 complained about the complained about being charged for both programs twice.

Kevin1: ... so now I still gotta pay even though I got a waive to put me off for a year - that it's going to add more fees, instead of $\$ 450$, it's gonna be $\$ 700$ something.

\footnotetext{
${ }^{7}$ When foster children are in the care of the Department of Children and Families (n 2).
} 
Another example of adverse financial impact related to the domestic violence arrest is Michael's change in occupation. Michael reported that he worked as a heavy equipment operator and lost his job because he was jailed in another city, where he was vacationing with his wife and daughter when he was arrested. He reported that now he is trying to start a business as a handyman.

Michael: ... I lost a job making thirty-nine thousand $\$ 39,000$ a year...I was in jail; I couldn't go to work. I was in there a week almost, before somebody noticed I was in jail...sat in the jail cell...couldn't use the phone unless you have the number, and I didn't have nothin'... she [his wife] didn't wait for me for nothin'.. took [the money] I had in my pocket and left for Miami...

\section{Female Primary Aggressor / Mutual Aggression}

This theme materialized from five participants' interviews and relates to identification of their female partners as the aggressors in the incidents. As reported by participants, the women acted out of anger or jealousy, or both. Keith and John described incidents related to recent break-ups and involving anger and jealousy. Jonathan described an incident that was proximally precipitated by jealousy—-he was talking on the phone with his baby's mother-but was also within the context of his fiancé's unrelated ongoing anger.

Two women reportedly armed themselves with devices such as a knife, an automobile and toxic fluid. Three women were reported to be the primary aggressorsnot only related to the particular incident—-but in the relationship generally.

Kevin2 reported that his fiancé was angry and she was also the primary aggressor in the incident; but his behavior indicates that his fiancé's actions may have been selfdefense, which was discussed earlier. 
Jonathan's fiancé is an outlier in that her violence was the most extreme, although her motivations were not different from the other women who were reportedly primary aggressors. Jonathan's depiction of his fiancé included both motivations - anger and jealousy — and use of weapons (knife and car), and also retaliatory behavior.

Jonathan reported that his fiancé had a history of violence toward him, and used weapons, and that she also retaliated against him by damaging his rental house and ruining his clothes (as described later). Soon after his fiancé moved in with him, “...that's when we started arguing all the time:

Jonathan: ...so after we started arguing basically every week — she started getting mad and she hit me, keep hitting me and I would leave the house and after I come back, everything would be calm.

Jonathan described an altercation that he alleged was initiated by his girlfriend. During the incident, Jonathan reportedly moved the refrigerator in front of the door to keep her out, but his girlfriend allegedly pushed on it and he pushed it back and the refrigerator purportedly fell toward her, causing some injury.

Jonathan: ...When I started to leave out of the house, she grabbed me, she had grabbed the knife and tried to cut my finger... and I ran out and she...got in her car, and she hit me with her car...chased me down the street and hit someone's gate trying to hit me and then she tried to hit me again and she hit me and I fell over someone's gate...s I I ran back in the house....and I slid the refrigerator in front of the door... and she came back... and I kept asking, "can I get my key?'... and she pushed the door and the refrigerator was falling on me and I pushed it back and I guess it hit her, and I guess she started bleeding.... and I guess she called the police on me.

John described his ex-girlfriend's attack while he was playing dominos:

John: ...me across the street playing dominos. She said can I talk to you? So I walked to the car...So we had a discussion and I didn't like what she was sayin' so I ...walked away." And she called me back... and she threw something in my face...threw it all in my face, my eyes was burning; and I reached through the car 
window and grabbed her, I didn't hit her or nothing - I just grabbed her. And she called the police, said I assaulted her.

Keith and Chase reported that their female partners had a history of violence against them, which occurred when they were angry.

Keith reported that he assumed his ex-girlfriend was going to use violence against him again in the incident for which he was charged:

Keith: ... if she sees something she don't like, if she see me conversating with other people or mingling, she put her hands on me in public places... when me and her were dating, she slapped me in public ... I was separated with my exgirlfriend... and she started following me around... and I was there with a date... and she confronted the girl... And, I grabbed the girl's hand and we walked out... and [she] followed behind us as we were leaving and she ran up, I guess to get physical with me and the girl as we were leaving, and I gave her a shove in the face and she got upset about that and called the police. She made accusations that I beat her up.

Chase reported that his wife had a history of violence toward him:

Chase: ...once [their two-year old son died], it got worse; she started attacking...I'm like [her] personal punching bag ...her mom knows that my wife gets physical with me... and her mom tell her "you got to stop hitting him" because I took that for two years before I ever put my hands on her.

Kevin2 reported that his fiancé initiated the domestic violence incident:

Kevin2: ...she got real mad and she said she hate me and she punched me in my face three times and punched me in my chest about four times and I started to bleed and I pushed her off me...

Later, Kevin2 described his own actions in the incident, which indicates that his fiancé may have been acting in self-defense. Details are reported in the theme on Insight and Perception of Bias.

Male participants indicated that they did not report the domestic violence perpetrated against them. Although some participants identified their female partners as the primary aggressors or initiators of the violence, they reported that they did not call 
upon law enforcement for relief. For example, Jonathan “...didn't call the police because if she got a domestic violence charge, it would be hard for her...and I was trying to look out for her." Similarly, Chase responded, "I didn't want to get her in no trouble...cause you going to feel real bad that your wife sittin' in jail because she slapped you and it didn't really hurt you." Keith noted, "I think it's an ego thing; plus, men don't want to see our women go to jail."

\section{Insight and Perceptions of Bias}

Participants often exhibited lack of insight in their reports of the context and precipitants of the violent incidents. Although they did not deny the violent behavior, most participants simply described the incidents as the dynamic actions unfolded, without reflection on the impact of their own behaviors - as if their responses were reasonable reactions under the circumstances. Their accounts of the incidents were presented as justifications for their actions.

In two cases, participants disavowed violence against women, yet describe they had been mandated to BIPs for their aggressive behavior toward their female partners:

Jonathan: ...my mom just say one thing: "don't put your hands on no female," and with all my girlfriends, that's one thing I won't do.

Jonathan: ... she did so much to me, she cut my fingers, she wrecked both my cars - I didn't get mad at her for nothin'. I did Uber with my car, so I had to stop; everything just stopped.

Chase: ...I saw that growing up...my mom's husband used to get drunk...get physical with her...so that's why I vowed not to do that...hit women.

Jonathan reported that he was attempting to escape his fiancé's violence by pushing the refrigerator in front of the door after she left, but that his fiancé was pushing 
on the other side to get in, "and I pushed it back and I guess it hit her, and I guess she started bleeding... and I guess she called the police on me.”

Although Chase "...vowed not to...hit women," in his description of the violent incident, he reported, "So, she slapped me again, so that's why I struck her back."

Michael described physically removing his wife from a social situation where she had become belligerent because she was inebriated. Michael did not recognize the relevance of his behavior, "I grabbed her by the arm and I pulled her into our room." Nor did he acknowledge the extent of his aggression when he reported that a bruise appeared on his wife's arm that she exhibited to the police.

Santana's recitation of the stalking incident for which he was arrested reveals that he did not recognize his stalking and harassing behavior, nor did he perceive the efforts taken to avoid him by the young woman:

Santana:...during the time that we got to know each other... people [were] telling her that I wasn't the right guy for her and stuff like that... She would listen to other people... So, people in the neighborhood were telling her that I was stalking her and stuff like that. And one time she told me she was going out of town, so I took it upon myself to go knock at the door and ask her mom was she back. Her mom said she wasn't back at that time, so I came back a couple of times and when she knows I was fixin' to get off probation, she goes and gets a restraining order against me because of the type of temper I got. I never hit her; I was always good to her. That's basically about it. So that's what got me here right now.

In addition, Santana did not understand stalking, and confused the behavior with voyeurism:

Santana: ...what I don't understand is why if a guy try to go back and try to talk to a girl, to try to patch things up - even if she doesn't want to talk right then and there-why is that stalking? What is stalking? I'm not in the bushes with binoculars watching her take showers and shit like that."

Santana further expressed his perplexity: 
Santana: ... why would you want to go down there and have a restraining order against me after all I did for you and the kids?

Santana explained that he had already been to a Batterers Intervention Program for another unrelated incident, and he was interested in finding out whether he could use that experience as credit for this new mandate to attend a Batterers Intervention Program.

Santana did not recognize that the purpose of the BIP was to prevent recidivism and that his re-assignment to a BIP was because his violent behavior occurred again.

In the following passage, Kevin2 described forceful behavior-possibly attempted sexual assault — and yet denied that his intention was aggression:

Kevin2: ... she punched me... and I started to bleed and ... we just got into a scruffle and I tried to give her ... affection ... and...the altercation got worse, I did get angry and I did get upset and I was hurt... and she... run outside and she caused... a scene... and so...I just picked her up over my shoulder and carried her... back to the apartment... you're causing a scene for no reason-I'm not trying to keep you here, I'm not trying to hold you hostage. [emphasis added]

Throughout his interview, Kevin2 continued to depict his fiancé as the aggressor, but did not view his aggressive behavior as relevant:

Kevin2: ... she broke the tv inside the house and she went outside and the police came;... It was the fact that she was crying and...distraught and...acting like the victim and I never wanted to hurt her at all. It wasn't my intention...the first thing I did when I got in the apartment was smash her phone - I was so pissed that she had a cold expression for no reason...trying to show her I love her, trying to beg her... trying to get her back to our apartment.

Kevin2's account of the incident for which he was arrested contains contradictory statements that both admit and deny responsibility for the domestic violence incident.

Perceptions of bias. Seven of the ten participants articulated beliefs that their experiences were unfair and reflect a bias in favor of women in the domestic violence justice system response. Despite acknowledgment of their own violent actions, they 
believed their behaviors were justified. Participants reasoned that because they were reacting to aggressive provocations, their violent actions were not unlawful.

Chase: ...the officer told me why...because you have to call first. I said, 'you know, I took this for a long time, officer'...And he say, "so why didn't you call us?" And I said, "I understand that's your job." ...It was my first time being arrested.

Jonathan: I was like, I ain't do nothing wrong-- I just didn't call the police on her...

Kevin2: And the police officer said, "do you want me to take him in?" at that point I realized I had no power whatsoever--if a woman's upset and you have a dispute of any kind, you are able to get arrested - I had blood on my shirt, but they didn't care that it was mine. (P6, 23:25)

Michael protested that his recitation of the incident and evidence was disregarded.

Michael was arrested while vacationing with his wife and toddler daughter in another Florida city. He reported that they were poolside one evening and his wife was drunk and became belligerent toward other guests.

Michael:...so I grabbed her by her arm and I pulled her into our room... and she started running. She ran to the front desk, called the cops on me. Said, "look at my arm," showed the bruise, and I went to jail for it.

Michael was arrested and reported that his wife returned to Miami and that he remained in jail for a week without his phone and couldn't "call unless you know the number." Finally, his sister discovered his whereabouts and posted his bail. Michael was angry during the interview and cited bias by the police:

Michael: I told the officers, look at the camera...they don't care. She called and you're going.

Michael complained further about how the system is biased toward women:

Michael: ... you call the cops to your house, you say you need a restraining order... you go to the courthouse and you say 'I'm scared to live there' and they 
help you re-locate...basically, she got $\$ 2,500$ for putting a restraining order on me.

Similarly, John expressed frustration that the police disregarded witnesses and expressed bias in the system in favor of women who report domestic violence.

John: ... I had a bunch of witnesses that told the police what happened 'cause I was playing dominoes. But they still ...made me go to the battery intervention program...[she] need to go too, because it's really not fair; I'm going to jail; I'm losing everything and I didn't do nothing... I protected myself. You battered me. But because you're a woman you get to walk away and I come.

Keith also expressed frustration about the bias toward women in allegations of domestic violence. He complained about unfairness because the police do not conduct a "thorough investigation," such as obtaining video from cameras and interviewing witnesses at the sports bar where the incident occurred.

Keith: ....and it's not fair that I have to go through this, because I'm not the abuser...I think the system need to design a better law system when it comes to the women not always have to have the rights to say that they was abused without a thorough investigation first. It's not fair for a lot of people, they can just call the police and you have to give up all your rights because of what they say verbally without a thorough investigation-you know, did this really happen? Nothing was ever investigated...It's not a fair system. It's really not. It's very shameful, very hurtful and I think a thorough investigation needs to be done before action is taken place.

Joshua complained that the system is biased because it is designed for entrapment:

Joshua: ...I feel like things are set up to catch people like me who have no intention of being a criminal; no intention of causing people harm, no intention of getting into trouble and they try to make it easier for them to catch you off guard and blame you for doing something that you really weren't doing.

Most participants expressed justification for their violence by referencing their partners' actions and believed the justice system unfairly held them accountable. Their failure to abstain from responding with violence contributed to their arrests. 


\section{Findings Related to Severity of Violence and Severity of Injuries}

Another area of inquiry during the interviews related to the severity of the violence and the severity of any injuries. Important factors to consider when assessing for appropriate interventions in cases of domestic violence relate to these factors, which have been identified as important indicators of lethality risk (Campbell, Webster, KoziolMcLain, Block, Campbell, Curry...Laughon, 2003; Ehrensaft, Moffitt \& Caspi, 2004; Kingsnorth, 2007). According to the participants' accounts, the domestic violence incidents did not include their use of weapons such as guns or knives, nor were injuries to their partners severe (i.e., did not require hospitalization nor medical care for wounds). However, two of the partners were pregnant and needed obstetrical check-ups.

Kevin2 was charged with use of a "deadly weapon," because during the heated incident, which included him tackling his girlfriend and restraining her, he pursued her with his car and she believed he was trying to hit her with the car.

Kevin2: ... she ended up leaving the apartment again, and she caused a scene and she left and I got in the car to chase her down, not to chase her down to run her over, but the case says I used a deadly weapon as far as my car, which wasn't the case at all...(P6:12)

Although Kevin2 did not acknowledge using his car to try to hurt his female partner, police charged him with that offense.

What would be helpful? Among the questions posed to participants near the end of the interviews, was an inquiry about what they thought would be helpful or would make the justice system's domestic violence response more fair. Most participants responded by referring to the unfair treatment they received from the system. John's response is representative of such sentiments: 
John: ...I would try to design a program [to] get the man's side of the story, cause all the programs are designed for the women to be the victim, but a lot of times the woman be the antagonizer. They start everything up and then they call the police and the man don't stand a chance... but they need to go too, because it's really not fair; I'm going to jail; I'm losing everything and I didn't do nothing ...I protected

myself. You battered me. But because you're a woman you get to walk away and I come.

Two participants' suggestions differ from the complaints about the system:

Chase suggested that men need to change their culture of overlooking their female partners' aggression, “...men have to change that culture —oh, that ain't hurt; she can hit me-she can get away with it..." Chase pointed out that by not taking action to address female aggression toward their male partners, their violent behavior will escalate and eventually men will defend themselves by striking back.

Keith suggested interventions for both partners:

Keith: ...I think they need more couple intervention programs where the couple need to go together, not just the person that's been accused of all the wrongdoing. Something that a couple can go to together; the courts should have it so that they both should see a counselor at the same time and the counselor can see both sides and hopefully make it better and if it can't get better, then let it go.

Keith's suggestion is similar to what has been recommended for couples who engage in situational domestic violence as opposed to domestic violence that is characterized by one partner exercising coercive controlling violence, also known as Intimate Terrorism (Stith, Rosen, McCollum, \& Thomsen, 2004).

\section{Status of Relationships}

As a result of the domestic violence incidents, seven participants reported that they were no longer in the same relationships. Two participants reported that they were 
still with the same partner at the time of the interviews, and one participant reported that although he was separated from his former fiancé, they "are trying to work things out." Of the seven participants who were no longer in the same relationships, two participants reported that they are in new relationships. The remaining five participants reported that they were not involved in romantic relationships at that time. Therefore, half of the participants are in relationships, whether previously existing or new; which means that there is risk for future domestic violence if interventions are not effective. It is worth noting that three participants reported that the domestic violence incidents occurred with former girlfriends, i.e., after the relationships had already ended. So, even if relationships have ended, participants still would benefit from effective conflict management skills because they engage in new relationships. 


\section{CHAPTER VI: DISCUSSION}

This study aimed to address an identified gap in the literature related to perspectives of male domestic violence offenders and specifically focused on contextual and proximal conditions related to the incidents for which they were arrested. Therefore, ten male domestic violence offenders were recruited and anonymously interviewed about their perspectives, which interviews focused on contextual factors - both distal and current, as well as proximal precipitants of the violent incidents toward their female partners.

Five of the ten men identified their female partners as the primary aggressors. From the perspectives of nine of the ten participants, their violence was justified. For the most part, the men exhibited limited insight into their violent behavior. Their recitations of the violent incidents were marked by anger, frustration and confusion; only one participant expressed "regret," and another acknowledged that his behavior was a “mistake." Reports of traumatic experiences by the participants and about some of their female partners were common.

\section{Distal Contextual Factors}

Trauma. Within six participants' accounts of distal contextual factors were traumatic childhood experiences such as abuse, witnessing domestic violence, social services interventions resulting in foster care placement or termination of parental rights and adoption to abusive family. Five of the ten men included reports of distal contextual factors of their female partners, such as childhood sexual molestation, witnessing domestic violence, and mental health disability resulting in involuntary hospitalization. 
Histories of childhood trauma may be an important clue in understanding how to intervene with people impacted by domestic violence. Although childhood trauma has been identified as one of many risk factors for adult domestic violence perpetration or victimization, the research regarding the neurobiological impact of trauma and traumainformed treatment is not integrated in the domestic violence literature.

Exploration of the childhood trauma literature reveals that it is prevalent and that its impact is highly consequential. Bessel van der Kolk reported that, "research has shown that traumatic childhood experiences are extremely common and have a profound impact on many different areas of functioning," including adult impulsivity and domestic violence $(2005$, p. 401$)$. Van der Kolk cited one study ${ }^{8}$ that found a "highly significant relationship" between childhood trauma and adult domestic violence, among various other serious sequelae such as suicide attempts and drug abuse $(2005,401)$. Trauma has been identified as a brain injury with neurobiological sequelae that can have life-long negative impact, such as faulty threat perception and depression (Nemeroff, 2002; Teicher, 2004; van der Kolk, 2005).

Given that traumatic childhood experiences have been found to be "extremely common," and that such trauma has serious negative impacts such as impulsivity, depression and faulty threat perception—all of which are arguably associated with domestic violence - theory development may well be furthered by an understanding of, and by research related to, the neurobiology of trauma.

${ }^{8}$ Adverse Childhood Experiences Study (ACE) by Kaiser Permanente and the Centers for Disease Control and Prevention. Felitti, V., Anda, R., Nordenberg, D., et al. (1998). Relationship of childhood abuse and household dysfunction to many of the leading causes of death in adults. American Journal of Preventive Medicine 14(4), 245-258. 
In Florida, when children witness domestic violence, their parents are charged by the Department of Children and Families ("DCF") with child maltreatment under "failure to protect," or "family violence threatens child." Such charges are addressed in juvenile dependency court, which usually mandates services to parents to address their violent behavior. Services provided are BIPs and safe shelters for victims (Florida Department of Children and Families). In recognition of its deleterious effect on children bystanders, social services interventions could strengthen its policy to include supportive counseling for children. With trauma-informed supportive counseling, children may avoid development of long lasting trauma effects described earlier.

\section{Current Contextual Factors}

Current contextual factors also were reported by participants, and included stressors such as reduced income, alcohol abuse, children with serious disabilities, intellectual disability and recent relationship break-ups. Such stressors were described by participants during their interviews and some were precipitants to the violence.

\section{Adverse Financial Impact}

An additional current stressor was identified by the participants' responses to demographic questions. All ten participants reported that they were either unemployed or had annual incomes below the 2018 Federal Poverty Guidelines for a family of four-$\$ 25,100$ (U.S. Department of Health and Human Services, 2018). In addition to their economic disadvantages, the justice system intervention for domestic violence resulted in more financial stressors. Three men reported that they lost their jobs due to domestic violence incarceration; one young man lost financial housing support from social services; and another young man was charged for two years of the BIP because he could 
not afford to attend the first year and was re-enrolled. Furthermore, five of the ten men reported that they returned to live with their mothers or parents after the domestic violence charges because they could not afford to support themselves anymore.

Such unintended financial burdens - especially among the participants who are already economically disadvantaged — can create stressors that contribute to discord in relationships. One participant acknowledged that his loss of a "good job" because of the domestic violence charges continued to be an issue in his marriage.

Although low socioeconomic status is a well known risk factor for domestic violence, BIPs are intended to prevent future domestic violence and thereby protect victims. Federal, state and local funds could provide relief by funding this protective measure, much the same as such funds currently support domestic violence shelters and programs for victims. Yet, the Violence Against Women Act (VAWA) — which includes a provision for grant funds to address domestic violence-including direct services to victims - has not usually allowed VAWA federal funds to be used to provide direct prevention services to offenders.

This policy contravenes the aim of the Violence Against Women Act of 1994 and subsequent reauthorizations - to prevent domestic violence and protect victims - and the well-established primary purpose of batterer intervention programs: victim safety (Adams, 2003; Domestic Relations, Florida Statutes, 2018; Price \& Rosenbaum, 2009). However, there appears to be interest in reconsidering this prohibition. In 2018, the Office of Violence Against Women awarded funds to provide prevention programming to incarcerated offenders in Pinellas County, Florida ("Pinellas receives federal grant," 2018). 
Policy is needed to publicly fund treatment of this public health problem at its source - the offenders. Providing public support would expand access to batterer intervention programs and avoid unintended adverse financial impacts on people who are economically disadvantaged. Public support would stabilize programs that struggle financially ${ }^{9}$ and could provide resources for piloting different approaches to batterer intervention (Price \& Rosenbaum, 2009). In particular, programs that provide conflict management and communication skills could be of great benefit to couples struggling with situational domestic violence.

\section{Female Partner Aggression}

Five of the ten participants identified their female partners as the primary aggressors. Although none of those five men reported their female partners' aggression to law enforcement officials, three explained their reticence to report the violence of the women because they did not want them to go to jail. Reports of female partner aggression are not new, and rates of female aggression against their male partners have been shown to be similar to rates of male perpetration on female partners (Ehrensaft, Cohen, Smailes, Chen \& Johnson, 2003; Hamel, 2010; Holtzworth-Munroe, 2005; O’Leary \& Smith-Slep, 2006).

According to O'Leary and Smith-Slep, "women may often be the first to escalate a conflict with violence..." however, such escalation may “disinhibit men's physical aggression," which can result in serious injury to women (2006, p. 346). Unilateral imposition of Batterer Intervention Programs for men accused of situational domestic

\footnotetext{
${ }^{9}$ More than half of all BIPs (54\%) were found to be solely funded by batterer payments. Approximately $87 \%$ of BIPs reportedly relied at least partly on fees paid by batterers. Sliding scale fees and high attrition rates reportedly caused BIPs to struggle financially and some failed to thrive (Price and Rosenbaum, 2009).
} 
violence in their heterosexual relationships has not proven effective. Furthermore, there is reason to believe that women may initiate violence and their male partners do not report it.

Aside from cases of coercive controlling abusers (intimate terrorism), effective interventions have yet to be confirmed - although promising programs for couples have been reported; and could be piloted under carefully monitored conditions, as has been previously reported (McCollum \& Stith, 2008; Stith, Rosen, McCollum, \& Thomsen, 2004).

Yet, couples programs have been widely denounced. In fact, a special condition of the U.S. Office of Violence Against Women grants is that grant recipients specifically agree not to require victims to participate in couples counseling — which is considered among other prohibited activities that, “...may compromise victim safety” (General Terms and Conditions for Grants, 2017).

It is widely accepted that couples counseling is not appropriate for coercive controlling domestic violence (intimate terrorism), because one partner is the aggressor and uses intimidation, threats and violence against the non-violent partner to isolate and control that partner. Hence, such criminal behavior is appropriately responded to by the criminal justice system with special efforts to protect and ensure the safety of the nonviolent partner.

However, situational couples violence has been documented and couples counseling has been found to be viable in cases when couples are inclined toward such help (McCollum \& Stith, 2008; Stith, Rosen, McCollum, \& Thomsen, 2004). Policy such as that of the U.S. Office of Violence Against Women prohibiting grant funds for 
couples counseling fails to take into account research that documents the existence of situational couples violence, and also fails to acknowledge research that has shown successful couples intervention under carefully managed and monitored conditions.

\section{Perceptions of Bias and Limited Insight}

Five of the ten participants raised issues related to bias in the system's response to domestic violence. Some said that police officers ignored their statements or ignored evidence such as video camera recordings; others reported that domestic violence incidents need more thorough investigation, and some said that both partners in the relationship should receive intervention. Yet, most of the participants did not deny their violent behavior, and even if their complaints about biases were rectified, that would not have exonerated them.

Justifications as internal prompts. The participants' recitations of their reasons for the violence were presented as justifications for their behavior. Justifications differ from excuses in that excuses blame external factors such as drunkenness or stress (Mullaney, 2007). Justifications, on the other hand, are internal triggers that elicit a response (Mullaney, 2007; Reitz, 1997). This begs the question about what triggers the response in the first place? (Reitz, 1997). Not everyone responds to such situations or provocations with violence. What previous experiences or interpretations of behavior led to a violent reaction? An exploration of distal contextual factors-including traumatic experiences - could elucidate important areas for effective intervention and for understanding the etiology of domestic violence.

Police policy for responding to domestic violence. In 1999, Florida received federal funding through the Violence Against Women Act grants funding program. 
Among the grant purposes was to develop and implement "more effective law enforcement policies for preventing and responding to domestic violence against women in Florida." As a result, a policy entitled, "Responding to Domestic Violence, Model Policy Number Two for Florida Law Enforcement: November 1999” (“Model Policy”) was established.

Among the provisions of the Model Policy are procedures for conducting domestic violence investigations, including, in pertinent part, sections entitled, "VI. OnScene Investigation," and "VII. Arrests." The section on arrests includes language that “...discourages dual arrests" and:

...Where there are allegations that each party assaulted the other, the officer shall determine whether there is sufficient evidence to conclude that one of the parties is the primary aggressor...

VII Arrests, G. 1., Model Policy

Florida statute 741.29 entitled, "Domestic violence, investigation of incidents," incorporates this policy into law.

The Model Policy also provides guidance regarding the determination of who is the primary aggressor:

Determine who is the primary aggressor, using the following factors and the officer's

judgment: extent of any injuries inflicted; fear of physical injury because of past or present threats; actions taken in self-defense or to protect oneself; history of domestic abuse perpetrated by one party against the other, and existence or previous existence of orders for protection.

VI On-Scene Investigation, C. 6.

The Model Policy also addresses the training of sworn officers including that they shall receive "competency-based training in domestic violence," and delineates the 
specific areas of competence, including, "means of identifying a primary aggressor." In addition, the Model Policy calls for, "Periodic or roll call training should address the components of this policy..."

XIV Training A., C.

Some participants in this study believed that bias was involved in their arrests. Police officers have discretion (“officer's judgment”) in determining the primary aggressor and hence, who will be arrested for a domestic violence offense. Although there is policy and legislation and required training, domestic violence is a complex phenomenon - and it is possible that officers may err in their judgment, and some officers may have attitudes about domestic violence that impact their judgments. Ideally, specialized units of sworn officers with an interest in domestic violence would be established. Personnel could receive additional specialized training in the dynamics of domestic violence. In addition, such units could be staffed with trained advocates to provide supportive services to families affected by domestic violence.

Furthermore, it could be helpful for the Department of Corrections to employ special case managers who meet with domestic violence offenders soon after their arrests to help ameliorate some of the unintended adverse consequences of their arrests. For example, Michael did not have his cell phone and could not recall any phone numbers, which resulted in his extended incarceration for one week. Personal items such as cell phones are routinely taken from arrested persons, inventoried and stored pending their release. If there was a case manager, the needed phone numbers may have retrieved to help him bond out earlier and to contact his employer and possibly avoid loss of his job. 


\section{Findings Related to the Bell \& Naugle IPV Contextual Framework}

Results from this study lend some support to the contextual framework proposed by Bell \& Naugle (2008). That is, male physical violence perpetration against their female partners was associated with every major category of the contextual framework except one: Verbal Rules. Some provisional codes were not connected ("grounded") to the data. That is, some factors within the major categories that were proposed to be causes of, or associated with, incidents of domestic violence were not factors identified by participants in their interviews and those codes were eliminated. That is not to say that the framework's factors are disproved; simply that this small sample of male offenders did not report those factors.

Given reports from participants related to their female partners' contextual factors, the framework could be enhanced by including context as it relates to female partners. By examining context of domestic violence from the antecedents and precipitants related only to the offender, the context of the violent episode is incomplete. Ideally, using the contextual framework to document the female partners' perspectives of the same incident, including their perspectives as they relate to conditions of their male partners, would provide valuable clues for prevention and intervention efforts. Finally, adverse financial impacts could be added to the framework's Consequences category.

\section{Limitations}

This study has a number of limitations. Most importantly, generalizability of findings is limited because this is a small qualitative study. Qualitative methodology is designed to identify concepts and theories that are characteristic of the population under 
study. However, prevalence of the concepts identified in this study requires validation made in a larger quantitative design

In this study the sample was particularly small, as has been seen in related studies because of the difficulty in obtaining participants (Catlett, Toews and Walilko, 2010; Fenton and Rathus, 2009; Flink and Paavilainen, 2008; Goodrum, Umberson and Anderson, 2001; Reitz, 1999; Wood, 2004). However, there is value in information gained from in-depth interviews - even from a small group. Nevertheless, these findings must be interpreted with caution.

Another limitation of the study is the ethnic composition of respondents. Eight of the ten participants were of African origin, and two were Latino. Although these groups are understudied, it would be important to conduct a similar study with other populations.

Finally, due to the anonymity of participants, it was not possible to add quality control approaches such as member-checking to the research protocol. Member checking would have made the findings more robust, but this would have required additional data collection with new, similar participants, which was extremely difficult—or it would have required less stringent confidentiality, which could have exposed participants to additional risk — and would have likely further inhibited participant recruitment. The potential for added value of such additional approaches was not deemed to be sufficient to warrant the expense and challenges presented by recruitment.

However, efforts were made to strengthen the quality of the data. The study was presented as an opportunity for the men to tell their side of what happened. To encourage candid responses, no identifying information of participants was collected. Participants were informed that no law enforcement officials, court personnel or BIP providers would 
know about their participation. Interviews were conducted in a separate area that was not visible by any such staff. Participants were also informed that their participation would not have any effect on their justice system cases. The interviews were conducted by the investigator, who is a Clinical Social Worker with eighteen years' experience in the field of domestic violence and skills in establishing rapport. Thus, the interviewer interacted with participants in an open and respectful manner and informed participants that their perspectives were valuable and would contribute to understanding how to help in cases of domestic violence.

\section{Implications for Social Work.}

Domestic violence is pertinent to the field of social work. Social work values the importance of human relationships and social justice. Domestic violence is a complex social problem that affects all social systems levels — within which social workers are trained to examine. Research related to domestic violence is well within the purview of social work.

In addition, social work practitioners are trained to assess and intervene with individuals and families, and to engage at the micro-, meso- and macro- social systems levels. Social workers can identify needs and facilitate access to community resources, and to the extent that systemic bias is documented, social workers are committed to advancing social justice and could advocate for change.

Social workers can design intervention programs that more appropriately target identified needs of domestically violent couples and can also engage in evaluation of effectiveness of such programs. 


\section{Future Directions}

Although establishing and ensuring safety takes the highest priority in cases of domestic violence, a criminal justice response alone is inadequate to address this serious public health issue. The contextual and proximal accounts of incidents of situational domestic violence in this study provide clues for responses related to social systems responses.

Safety considerations and recruitment are impediments to research that aims to elicit contextual and proximal factors related to situational domestic violence incidents. Yet, such research on contextual and proximal factors from the perspective of the offenders are a gap in efforts to understand domestic violence and to develop domestic violence theory. Ideally, more studies with larger samples that include perspectives of both partners in cases of situational heterosexual domestic violence would reveal whether this study's findings can be replicated. For example, if a significant number of cases include allegations of female partner aggression, then it is possible that incidents of situational domestic violence are incorrectly and disproportionately attributed to male partners in heterosexual relationships — which also implies ineffective interventions - and inhibits theory development.

In addition, studies that examine proximal and contextual factors in incidents of situational domestic violence from each partner's perspective — with a view toward exploring whether certain factors interact with specific other factors-could contribute to prediction efforts in domestic violence theory development.

Future studies that provide "idiographic assessment" of domestic violence precipitants and connect them with "general setting events," has been called for by 
O'Leary \& Smith-Slep (2006, p. 347). Such studies also could help predict the circumstances under which a domestic violence incident may occur.

Future studies are needed with much larger samples to establish the prevalence of adverse financial impacts, female partner aggression and system bias. Especially, research aimed at determining the prevalence of childhood trauma in cases of domestic violence may lead to important findings related to theory development. Given that traumatic childhood experiences are "extremely common," and that "a highly significant relationship" between childhood trauma and adult domestic violence has been found, an understanding of the neurobiological impact of trauma could be a vital component of domestic violence theory development (van der Kolk, 2005, p. 401).

Finally, the voices of domestic violence offenders themselves also can provide insight about potential directions for future research. One study participant suggested several social factors that may impinge upon men who abuse their female partners when he reflected about his experience of witnessing domestic violence against his mother:

It's that men - some men that get violent with their spouse, they have other issues, so they take it out on her. And that's probably the only thing like, he can control. He don't have no control at his job, probably he don't have no control over his health, or his drinking or smokin' or anything - he thinks it's the only thing I can control. So, that's kinda what I saw when I was growin' up. You don't have no grips on anything but my mom. My mom, he feel good about. 


\section{REFERENCES}

Adams, D. (2003). Treatment programs for batterers. Clinics in Family Practice, 5(1), 159. doi: $10.1016 / \mathrm{S} 1522-5720 \% 2802 \% 2900079-\mathrm{X}$

Anderson, M.A., Gillig, P.M., Sitaker, M., McCloskey, K., Malloy, K. \& Grigsby, N. (2003). Why doesn't she just leave?: A descriptive study of victim reported impediments to her safety. Journal of Family Violence, 18 (3), 151-155. doi: 10.1023/A:1023564404773

Atlas.ti Scientific Software GmbH, v. 7. (2013). Qualitative Data Analysis. https://atlasti.com

Austin, J. B. \& Dankwort, J. (1999). Standards for batterer programs: a review and analysis. Journal of Interpersonal Violence. 14(2), 152-168. doi: $10.1177 / 088626099014002004$

Babcock, J. C., Green, C. E., \& Robie, C. (2004). Does batterers' treatment work? A meta-analytic review of domestic violence treatment. Clinical Psychology Review, 23(8), 1023-1053. doi:10.1016/j.cpr.2002.07.001

Bandura, A., D. Ross, S. Ross (1963). Vicarious reinforcement and imitative learning. The Journal of Abnormal and Social Psychology, 67(6), 601-607. doi: $\underline{10.1037 / \mathrm{h} 0045550}$

Barry, C.A. (1998). Choosing qualitative data analysis software: Atlas/ti and Nudist compared. Sociological Research Online, 3 (3). doi: 10.5153/sro.178

Beck, A.T., Rush, A.J., Shaw, B.F., Emery, G. (1979). Cognitive therapy of Depression. New York, NY: Guilford Press

Belfrage, H. \& Strand, S. (2008). Structured spousal violence risk assessment: Combining risk factors and victim vulnerability factors. International Journal of Forensic Mental Health, 7(1), 39-46. doi: 10.1080/14999013.2008.9914402

Bell, K. M., \& Naugle, A. E. (2008). Intimate partner violence theoretical considerations: Moving towards a contextual framework. Clinical Psychology Review, 28(7), 1096-1107. doi:10.1016/j.cpr.2008.03.003

Belus, J., Wanklyn, S., Iverson, K., Pukay-Martin, N., Langhinrichsen-Rohling, J. \& Monson, C. (2014). Do anger and jealousy mediate the relationship between adult attachment styles and intimate partner violence? Partner Abuse 5(4), 388-406. 
Birkley, E., \& Eckhardt, C.I. (2015). Anger, hostility, internalizing negative emotions, and intimate partner violence perpetration: A meta-analytic review. Clinical Psychology Review, 37, 40-56. doi: 10.1016/j.cpr.2015.01.002

Blau, P. (1964). Justice in social exchange. Sociological Inquiry, 34(2), 193. Retrieved: http://search.proquest.com.ezproxy.fiu.edu/docview/60602031? accountid=10901

Bowen, E. (2011). The Rehabilitation of Partner-Violent Men. West Sussex, UK. WileyBlackwell.

Breiding, M.J., Basile, K.C., Smith, S.G., Black, M.C., Mahendra, R. R. (2015). Intimate Partner Violence Surveillance: Uniform Definitions and Recommended Data Elements, Version 2.0. Atlanta: National Center for Injury Prevention and Control, Centers for Disease Control and Prevention http://www.cdc.gov/violenceprevention/pdf/intimatepartnerviolence.pdf.

Breiding, M.J., Chen J., \& Black, M.C. (2014). Intimate Partner Violence in the United States - 2010. Atlanta, GA: National Center for Injury Prevention and Control, Centers for Disease Control and Prevention. Retrieved 6/19/2018.http://www.cdc.gov/violenceprevention/pdf/cdc _nisvs_ipv_report_2013_v17_single_a.pdf.

Bronfenbrenner,U. (1999). Measuring environment across the life span: Emerging methods and concepts. In S.L.Friedman \& T. D. Wachs (Eds.). Washington, D.C.: American Psychological Association Press

Brown, J., James, K., \& Taylor, A. (2010). Caught in the rejection-abuse cycle: Are we really treating perpetrators of domestic abuse effectively? Journal of Family Therapy. 32, 280-307. doi: 10.1111/j.1467-64272010.00494.x

Buttell, F. F. P. (2002). Psychological and demographic predictors of attrition among batterers court ordered into treatment. Social Work Research, 26(1), 31-41. doi:10.1093/swr/26.1.31

Campbell, J., Webster, D. \& Glass, N. (2009). The Danger Assessment: Validation of a lethality risk assessment instrument for intimate partner femicide. Journal of Interpersonal Violence. 24, 653-674. doi: 10.1177/0886260508317180

Campbell, J., Webster, D., Koziol-McLain, J., Block, C., Campbell, D., Curry, M. ... Laughon, K. 2003. Risk factors for femicide in abusive relationships: Results from a multisite case control study. American Journal of Public Health, 93(7), 1089-1097 doi: 10.2105/AJPH.83.7.1089 
Caetano, R.,Field, C.A., Ramisetty-Mikler, S., \& McGrath, C. (2005). The 5-year course of intimate partner violence among white, black and hispanic couples in the United States. Journal of Interpersonal Violence, 20(9), 1039-1057. doi: $10.1177 / 0886260505277783$

Cattaneo, L.B., Bell, M.E., Goodman, L.A. \& Dutton, M.A. (2007). Intimate partner violence: Victims' accuracy in assessing their risk of re-abuse. Journal of Family Violence. 22(6) 429-440 doi: 10.1007/s10896-007-9097-8

Carney, M. M., PhD., \& Barner, J. R., PhD. (2012). Prevalence of partner abuse: Rates of emotional abuse and control. Partner Abuse, 3(3), 286-335 doi: 10.1891/1946$\underline{6560.3 .3 .286}$

Carney, M. M., \& Buttell, F. (2006). Exploring the relevance of interpersonal dependency as a treatment issue in batterer intervention. Research on Social Work Practice, 16(3), 276-286. doi: 10.1177/1049731505282836

Catlett, B., Toews, M., \& Walilko, V. (2010). Men's gendered constructions of intimate partner violence as predictors of court-mandated batterer treatment drop out. American Journal of Community Psychology, 45(1-2), 107-123. doi: $10.1007 / \mathrm{s} 10464-009-9292-2$

Cavanaugh, K., Dobash, R.E., Dobash, R.P. \& Lewis, R. (2001). Remedial Work: Men's strategic responses to their violence against intimate female partners. Sociology 35(3), 695-714. doi: 10.1017/S0038038501000359.

Cavanaugh, M. M., \& Gelles, R. J. (2005). The utility of male domestic violence offender typologies: New directions for research, policy, and practice. Journal of Interpersonal Violence: Concerned with the Study and Treatment of Victims and Perpetrators of Physical and Sexual Violence, 20(2), 155-166. doi:10.1177/0886260504268763

Centers for Disease Control and Prevention (CDC). 2003. Costs of intimate partner violence against women in the United States. Atlanta: CDC, National Center for Injury Prevention and Control. Retrieved 6/19/2018

https://www.cdc.gov/violenceprevention/intimatepartnerviolence/consequences.ht $\underline{\mathrm{ml}}$

Cogan, R. \& Porcerelli, J.H. (2003). Psychoanalytic psychotherapy with people in abusive relationships. Journal of Aggression, Maltreatment \& Trauma (7) 29-46. doi: 10.1300/J146v07n01_03

Corvo, K., Dutton, D. \& Chen, W. (2008). Toward evidence-based practice with domestic violence perpetrators. Journal of Aggression, Maltreatment \& Trauma. 16(2), 111-130. doi: 10.1080/10926770801921246 
Danis, F. (2003). Criminalization of domestic violence: what social workers need to know. Social Work, 48(2), 237-246. doi: 10.1093/sw/48.2.237

Davis, R., \& Taylor, B. (1999). Does batterer treatment reduce violence? A synthesis of the literature. Women \& Criminal Justice, 10(2), 69-93. doi:10.1300/J012v10n02_05

Dutton, D. G. (2006). Rethinking domestic violence. Vancouver: UBC Press.

Dutton, D. G., Hamel, J. \& Aronson, J. (2010). The gendered paradigm in family court processes: Re-balancing the scales of justice from biased social science. Journal of Child Custody, 7(1), 1-31. doi:10.1080/15379410903554816

Dutton, D. G. \& Painter, S. (1993). Emotional attachments in abusive relationships: A test of traumatic bonding theory. Violence and Victims, 8(2), 105-120. doi: 10.1891/0886-6708.8.2.105

Dye, J.F., Shatz, I.M., Rosenberg, B.A., \& Coleman, S. T. (2000). Constant comparison method: a kaleidoscope of data. The Qualitative Report, 4(1), 1-10. Retrieved from https://nsuworks.nova.edu/tqr/vol/iss1/8.

Echeburúa E., Fernández-Montalvo J., De Corral P., López-Goñi J.J. (2009). Assessing risk markers in intimate partner femicide and severe violence: a new assessment instrument. Journal of Interpersonal Violence. 6, 925-939. doi: $10.1177 / 0886260508319370$

Ehrensaft, M. K., Cohen, P., Brown, J., Smailes, E., Chen, H., \& Johnson, J.G. (2003). Intergenerational transmission of partner violence: A 20-year prospective study. Journal of Consulting and Clinical Psychology, 71(4), 741-753. doi: 10.1037/0022-006X.71.4.741

Ehrensaft, M.K., Moffitt, T. E., \& Caspi, A. (2004). Clinically abusive relationships in an unselected birth cohort: Men's and women's participation and developmental antecedents. Journal of Abnormal Psychology, 113(2), 258-270. doi: 10.1037/0021-843X.113.2.258

Elmquist, J., Shorey, R. C., Labrecque, L., Ninnemann, A., Zapor, H., Febres, J., ... Stuart, G. L. (2016). The relationship between family-of-origin violence, hostility, and intimate partner violence in men arrested for domestic violence: Testing a mediational model. Violence against Women, 22(10), 1243-1258. doi: $\underline{10.1177 / 1077801215621177}$ 
Feder, L. \& Wilson, D. B. (2005). A meta-analytic review of court-mandated batterer intervention programs: Can courts affect abusers' behavior? Journal of Experimental Criminology, 1(2), 239-262. doi: 20.1007/s11292-005-1179-0

Feder, L., Wilson, D.B. \& Austin, S. (2008). Court-mandated interventions for individuals convicted of domestic violence. 2008 (12) 1-45. Campbell Systematic Reviews. http://campbellcollaboration.org/lib/. doi: $\underline{10.4073 / \text { csr.2008.12 }}$

Feldman, C. \& Ridley, C. (2006). The etiology and treatment of domestic violence between adult partners. Clinical Psychology: Science and Practice: 2(4), 317-348 doi: 10.1111/j.1468-2850.1995.tb00047.x

Felitti, V., Anda, R., Nordenberg, D., Williamson, D., Spitz, A., ...Marks, James. (1998). Relationship of childhood abuse and household dysfunction to many of the leading causes of death in adults: The adverse childhood experiences (ACE) study. American Journal of Preventive Medicine, 14(4), 245-258. doi: 10.1016/S0749-3797(98)00017-8

Am J Prev Med. 1998;14(4):245 -258. https://doi.org/10.1016/S0749-3797(98)00017-8. 1998 American Journal of Preventive Medicine

Fenton, B., \& Rathus, J. H. (2010). Men's self-reported descriptions and precipitants of domestic violence perpetration as reported in intake evaluations. Journal of Family Violence, 25(2), 149-158. doi: 10.1007/s10896-009-9278-8

Ferraro, K. J. (1996). The dance of dependency: A genealogy of domestic violence discourse. Hypatia, 11(4), 77-91. doi:10.1111/j.1527-2001.1996.tb01036.x

Finkel, E. \& Hall, A. (2018). The $\mathrm{I}^{3}$ model: a metatheoretical framework for Understanding aggression. Current Opinion in Psychology, 19, 125-30. doi: 10.1016/j.copsyc.2017.03.0132352-250X/

Finkel, E., Slotter, E., Pond Jr., R., DeWall, C., McNulty, J., \& Atkins, D. (2012). Using $\mathrm{I}^{3}$ to clarify when dispositional aggressiveness predicts intimate partner violence perpetration. Journal of Personality and Social Psychology, 102(3), 533-549. doi: $10.1037 / \mathrm{a} 0025651$

Flick, U., Kvale, S., Angrosino, M.V. \& Barbour, R.S. (2007). Designing qualitative research. Sage Publications, Ltd.

Flinck, A. \& Paavilainen, E. (2008). Violent behavior of men in their intimate relationships, as they experience it. Men's Health, 2(3), 244-253. doi: $10.1177 / 1557988308321674$ 
Florida Department of Children and Families. https://www.myflfamilies.com/ service-programs/domestic-violence/

Florida Statutes, (1995). Retrieved 6/28/2018 from: https://flsenate.govLaws/Statutes/ $2011 / 741.28$

Florida Statutes, (1995). Retrieved 1/13/2019 from: http://www.leg.state.fl.us/statutes/index.cfm?App_mode=Display_Statute\&Searc

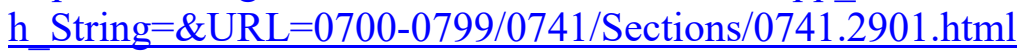

Florida Statutes, (2018). Requirements for batterers' intervention programs, Title XLIII, Chapter 741, 741.325 (1)(a), retrieved 5/19/2019 from: http://www.leg.state.fl.us/Statutes/index.cfm?App_mode=Display_Statute\&Searc h_String=\&URL=0700-0799/0741/Sections/0741.325.html

Flynn, A., \& Graham, K. (2010). "Why did it happen?” A review and conceptual framework for research on perpetrators' and victims' explanations for intimate partner violence. Aggression and Violent Behavior, 15(3), 239-251. doi: 10.1016/j.avb.2010.01.002

Ford, K., Oberski, I., \& Higgins, S. (2000). Computer-aided qualitative analysis of interview data: Some recommendations for collaborative working. The Qualitative Report [On-line serial], 4(3/4). Available: http://www.nova.edu/ssss/QR/QR4-3/oberski.html

Forgey, M.A., Badger, L., \& Krase, K. (2011). The development of an evidence based assessment protocol for intimate partner violence in the U.S. Army. Journal of Evidence-Based Social Work. 8(3) 323-328. doi: 10.1080/ 15433714.2011.533946

Frye, N. E., \& Karney, B. R. (2006). The context of aggressive behavior in marriage: A longitudinal study of newlyweds. Journal of Family Psychology, 20(1), 12-20. doi:10.1037/0893-3200.20.1.12

Gondolf, E. (2000). Reassault at 30-Months after Batterer Program Intake, International Journal of Offender Therapy and Comparative Criminology, 44, 111. http://www.iup.edu/maati/publications/outcomeabstracts.shtm\#outcome4

Gondolf, E. W. (2002). Service barriers for battered women with male partners in batterer programs. Journal of Interpersonal Violence, 17(2), 217-227.

Gondolf,, E. W. (2009, December). The survival of batterer programs? Responding to "evidence-based practice" and improving program operation. In Institute of Justice and Family Violence Prevention Fund Policy Symposium: Batterer Intervention: Doing the work and measuring the progress, Bethesda, MD. 
Graham-Kevan, N. \& Archer, J. (2003). Intimate terrorism and common couple violence: A test of Johnson's predictions in four British samples. Journal of Interpersonal Violence, 18, 1247-1270. doi: 10.1177/0886260503256656

Grossman, S.F. \& Lundy, M. (2007). Domestic violence across race and ethnicity: Implications for social work practice and policy. Violence Against Women, 13(10), 1029-1052. doi: 10.1177/1077801207306018

Hamel, J. (2010). Do we want to be politically correct, or do we want to reduce partner violence in our communities? Partner Abuse, 1(1), 82-91. doi: 10.1891/19466560.1 .1 .82

Hasstedt, K. \& Rowan, A. (2016). Understanding intimate partner violence as a sexual and reproductive health and rights issue. Guttmacher Policy Review. 9. ISSN: 1944-902X Online ISSN: 2163-0860.

Heise, L. (2011). What works to prevent partner violence: An evidence overview (ISBN: 978090265785 2). Retrieved 7/25/2018 http://strive.1shtm.ac.uk/system/files/attachments/What $\% 20$ works $\% 20$ to $\% 20$ preve nt\%20partner\%20violence.pdf

Healey, K., Smith, C., O'Sullivan, C., \& Abt Associates. (1998). Batterer intervention: Program approaches and criminal justice strategies. (Program Description/Evaluation No. NCJ 168638). Washington, D.C.: U.S. Dept. of Justice, NIJ Pub. https://www.ncjrs.gov/txtfiles/168638.txt

Holtzworth-Munroe, A. (2005). Female perpetration of physical aggression against an intimate partner: A controversial new topic of study. Violence and Victims, 20(2), 251-9. doi. 10.1891/088667005641

Holtzworth-Munroe, A., Meehan, J. C., Herron, K., Rehman, U., \& Stuart, G. L. (2003). Do subtypes of maritally violent men continue to differ over time? Journal of Consulting and Clinical Psychology, 71(4), 728-740. doi:10.1037/0022006X.71.4.728

Holtzworth-Munroe, A. \& Stuart, G. (1994). Typologies of batterers: Three subtypes and differences among them. Psychological Bulletin, 116(3), 476-497. doi: 10.1037/0033-2909.116.3.476

Hughes, H., Massura, C., Anukem, O., \& Cattage, J. (2016). Women college students' reasons for engaging in psychological dating aggression: A qualitative examination. Journal of Family Violence, 31(2), 239-249. doi: 10.1007/s10896015-9758-y 
Jackson, S. Feder. L., Forde, D., Davis, R. C., Maxwell, D.D. \& Taylor, B.G. Batterer intervention programs: Where do we go from here? (Research Report, Washington, D.C., U.S. Department of Justice, National Institute of Justice, June 2003, NCJ 195079. Retrieved 7/25/2018, https://www.nij.gov/topics/crime/intimate-partnerviolence/interventions/pages/batterer-intervention.aspx

Jenson, J.M. \& Fraser, M.W. (2006). A risk and resilience framework for child, youth and family policy. In Jeffery Jensen and Mark Fraser (Eds). (2006). Social policy for children and families: A risk and resilience perspective. Thousand Oaks, CA: Sage Publications.

Johnson, M.P. (1995). Patriarchal terrorism and common couple violence: Two forms of against women. Journal of Marriage and the Family, 57(2), 283-294. doi: $10.2307 / 353683$

Johnson, M.P. \& Ferraro,K. J. (2000). Research on domestic violence in the 1990s: Making distinctions. Journal of Marriage and the Family; 62 (4), 948-963. doi: 10.1111/j.1741-3737.2000.00948.x

Johnston, J.R. \& Campbell, L.E.G.(1993). A clinical typology of interparental violence in disputed-custody divorces. American Journal of Orthopsychiatry, 63 (2), 190199. doi: $10.1037 / \mathrm{h} 0079425$

Jones, R. (1995). Why do qualitative research? It should begin to close the gap between the sciences of discovery and implementation. British Medical Journal, 311(6996), 2-2. doi: 10.1136/bmj.311.6996.2

Jones, A., \& Gondolf, E. (2002). Assessing the effect of batterer program completion on reassault: An instrumental variables analysis. Journal of Quantitative Criminology, 18(1), 71. doi:10.1023/A:1013244929733

Jones, E. E., Kanhouse, D. E., Kelley, H. H., Nisbett, R. E., Valins, S., \& Weiner, B (Eds.). (1972). Attribution: Perceiving the causes of behavior. New York, N.Y.: General Learning Press.

Jones, E.E. \& Nisbitt, R.E. (1972) The actor and the observer: Divergent perceptions of the causes of behavior. In E. E. Jones, D.E. Kanhouse, H.H. Kelley, R.E. Nisbett, S. Valins, \& B. Weiner (Eds.), Attribution: Perceiving the causes of behavior (pp.79-94). New York, N.Y.: General Learning Press.

Jouriles, E. N., \& O'Leary, K. D. (1985). Interspousal reliability of reports of marital violence. Journal of Consulting and Clinical Psychology, 53(3), 419-421. doi:10.1037/0022-006X.53.3.419 
Kazdin, A.E. (2003). Research design in clinical psychology, fourth edition. Boston, MA: Allyn \& Bacon.

Kelly, J. B., \& Johnson, M. P. (2008). Differentiation among types of intimate partner violence: Research update and implications for interventions. Family Court Review, 46(3), 476-499. doi:10.1111/j.1744-1617.2008.00215.x

Kingsnorth, R. (2006). Intimate partner violence: Predictors of recidivism in a sample of arrestees. Violence Against Women, 12(10), 917-935. doi:10.1177/1077801206293081

Kropp, P.R. \& Hart, S.D. (2000). The spousal assault risk assessment (SARA) guide: Reliability and validity in adult male offenders. Law and Human Behavior, 24(1), 101-118. doi: 10.1023/A:1005430904495

Langhinrichsen-Rohling, J., Huss, M. T., \& Ramsey, S. (2000). The clinical utility of batterer typologies. Journal of Family Violence, 15, 37-53.

Lawrence, E., \& Bradbury, T.N. (2001). Physical aggression and marital dysfunction: A longitudinal analysis. Journal of Family Psychology, 15(1), 135-154. doi: $10.1037 / 0893-3200$.

Lawson, D. M. (2010). Comparing cognitive behavioral therapy and integrated cognitive behavioral therapy/psychodynamic therapy in group treatment for partner violent men. Psychotherapy (Chicago, Ill.), 47(1), 122-133. doi: 10.1037/a001884.

Leisenring, A. (2008). Controversies surrounding mandatory arrest policies and the police response to intimate partner violence. Sociology Compass, 2(2), 451-466. doi:10.1111/j.1751-9020.2008.00095.x

Leone, J. M., Johnson, M. P. \& Cohan, C. L. (2007). Victim help seeking: Differences between intimate terrorism and situational couple violence. Family Relations, 56(5), 427-438. doi: 10.1111/j.1741-3729.2007.00471.x

Macgowan, M. J., \& Beaulaurier, R. L. (2005). Using qualitative data analysis software in teaching about group work practice. Journal of Teaching in Social Work, 25(12), 45-56.doi: 10.1300/j067v25n01_03

Mackun, P., Wilson, S., Fischetti, T., Goworowska, J., 2011. Population distribution and change: 2000 to 2010. No. C2010BR-01, 2010 Census Briefs. Retrieved from: http://www.census.gov/prod/cen2010/briefs/c2010br-01.pdf 
Magdol, L., Moffitt, T. E., Caspi, A., \& Silva, P. A. (1998). Developmental antecedents of partner abuse: A prospective-longitudinal study. Journal of Abnormal Psychology, 107(3), 375-389. doi: 10.1037/0021-843X.107.3.375

Malle, B.F., Knobe, J.M., Nelson, S.E. (2007). Actor-observer asymmetries in explanations of behavior: New answers to an old question. Attitudes and Social Cognition. 491-514. doi: 10.1037/0022-3514.93.4.491.supp

Max, W., Rice, D. P., Finkelstein, E., Bardwell, R. A., \& Leadbetter, S. (2004). The economic toll of intimate partner violence against women in the united states. Violence and Victims, 19(3), 259-72.

McCollum, E. E., \& Stith, S. M. (2008). Couples treatment for interpersonal violence: A review of outcome research literature and current clinical practices. Violence and Victims, 23(2), 187. doi:10.1891/0886-6708.23.2.187

Mears, D., \& Visher, C. (2005). Trends in understanding and addressing domestic violence. Journal of Interpersonal Violence, 20(2), 204. doi:10.1177/0886260504267739

Miles, M. B., \& Huberman, A. M. (1994). Qualitative data analysis: An expanded sourcebook. California Oaks: Sage.

Mullaney, J. L. (2007). Telling it like a man: Masculinities and battering men's accounts their violence. Men and Masculinities, 10(2), 222-247.

https://doi.org/10.1177/1097184X06287758

Musser, P. \& Murphy, C. (2009). Motivational interviewing with perpetrators of intimate partner abuse. Journal of Clinical Psychology 65(11), 1218-1231. doi: 10.1002/jclp

National Coalition Against Domestic Violence. https://ncadv.org/why-do-victims-stay. Accessed July 5, 2018.

National Crime Victimization Survey (2016). United States Department of Justice, Bureau of Justice Statistics. https://www.bjs.gov/index.cfm?ty=dcdetail\&iid=245. Accessed July 5, 2018.

National Intimate Partner and Sexual Violence Survey: 2010 Findings on Victimization by Sexual Orientation (2013). PsycEXTRA Dataset. doi: 10.1037/e541522013001

Neal, A. M. \& Edwards, K. M. (2017). Perpetrators' and victims' attributions for IPV: A critical review of the literature. Trauma, Violence \& Abuse, 18(3), 239-267. doi: $10.1177 / 1524838015603551$ 
Nemeroff, C. B. (2004). Neurobiological consequences of childhood trauma. The Journal of Clinical Psychiatry, 65(Suppl 1), 18-28.

O'Leary, S. G., Smith-Slep, A. M. (2006). Precipitants of partner aggression. Journal of Family Psychology, 20(2), 344-347. doi: 10.1037/0893-3200.20.2.344

Olsen, J. P., Parra, G. R., \& Bennett, S. A. (2010). Predicting violence in romantic relationships during adolescence and emerging adulthood: A critical review of the mechanisms by which familial and peer influences operate. Clinical Psychology Review, 30(4), 411-422. doi:10.1016/j.cpr.2010.02.002

Onwuegbuzie, A. J. \& Collins, K. M. T. (2007). A typology of mixed methods sampling designs in social science research. The Qualitative Report. 12(2), 281-316. Retrieved: http://files.eric.ed.gov/fulltext/EJ800183.pdf. Permanent url: http://www.nova.edu/ssss/QR/QR12-2/onwuegbuzie2.pdf

Padgett, D. K. (1998). Does the glove really fit? Qualitative research and clinical social work practice. Social work, 43(4), 373-381. doi: 10.1093/sw/43.4.373

Pence, E. \& Das Dasgupta, S. (2006). Re-examining 'battering': are all acts of violence against intimate partners the same? Developed by Praxis International, Inc. http://www.praxisinternational.org/files/praxis/files/ReexaminingBattering.pdf

Pence, E., \& Paymar, M. (1993). Domestic violence information manual the Duluth Domestic Abuse Intervention Project, New York: Springer Publishing Company, Inc. Retrieved from http://www.duluth-model.org/

Peralta, R. L., Tuttle, L. A., \& Steele, J. L. (2010). At the intersection of interpersonal violence, masculinity, and alcohol use: The experiences of heterosexual male perpetrators of intimate partner violence. Violence Against Women, 16(4), 387409. doi: 10.1037/0893-3200.20.2.344

Pinellas receives federal grant for batterer intervention programs, (2018, October 22). tbnweekly.com. Retrieved from:

https://www.tbnweekly.com/pinellas_county/article 25210342-d636-11e8-806b978050d2477b.html

Price, B. J. \& Rosenbaum, A. (2009). Batterer intervention programs: A report from the field. Violence and Victims, 24(6), 757-770. doi: 10.1891/0886-6708.24.6.757

Reitz, R. (1999). Batterers' experiences of being violent: A phenomenological study. Psychology of Women Quarterly, 23(1), 143- '65. doi: 10.1111/j.14716402.1999.tb00348.x 
Rennison, C. \& Planty, M. (2003). Nonlethal intimate partner violence: Examining race, gender, and income patterns. Violence and Victims, 18(4), 433-443. doi: 10.1891/0886-6708.24.6.757

Rennison, C. \& Welchans, S. (2000). National crime victimization survey special report: Intimate partner violence. Bureau of Justice Statistics, U.S. Department of Justice, National Archive of Criminal Justice Data, Dataset ICPSR 6406. http://www.ojp.usdoj.gov/bjs/

Rhatigan, D. L., Moore, T. M. \& Street, A. E. (2005). Reflections on partner violence: 20 years of research and beyond. Journal of Interpersonal Violence, 20(1), 82-88. doi: $10.1117 / 0886260504268599$

Rosenbaum, A., \& O'Leary, K. D. (1981). Marital violence: Characteristics of abusive couples. Journal of Consulting and Clinical Psychology, 49(1), 63-71. doi:10.1037/0022-006X.49.1.63

Saltzman L.E., Fanslow J.L., McMahon P.M. \& Shelley G.A. (1999). Intimate partner violence surveillance: Uniform definitions and recommended data elements, version 1.0. Atlanta (GA): National Center for Injury Prevention and Control, Centers for Disease Control and Prevention.

Saunders, D.G. (1996). Feminist-cognitive-behavioral and process-psychodynamic treatments for men who batter: interaction of abuser traits and treatment models. Violence and Victims, 11(4), 393-414. doi: 10.1891/0886-6708.11.4.393

Sheehan, K. A., Thakor, S. \& Stewart, D. E. (2012). Turning points for perpetrators of Intimate partner violence. Trauma, Violence \& Abuse, 13(1), 30-40. doi: $10.1177 / 1524838011426016$

Sherman, L. W. (2003). Reason for emotion: Reinventing justice with theories, innovations, and research-the American Society of Criminology 2002 presidential address*. Criminology, 41(1), 1-38. doi: 10.1111/j.1745-9125.2003.tb00980.x

Shorey, R. C., Cornelius, T. L., \& Bell, K. M. (2008). A critical review of theoretical frameworks for dating violence: Comparing the dating and marital fields. Aggression and Violent Behavior, 13(3), 185-194. doi:10.1016/j.avb.2008.03.003

Silveregleid, C. S. \& Mankowski, E. S. (2006). How batterer intervention programs work: Participant and facilitator accounts of processes of change. Journal of Interpersonal Violence, 21(1), 139-159. doi: 10.1177/0886260505282103 
Simons, R. L. \& Johnson, C. (1998). An examination of competing explanations for the intergenerational transmission of domestic violence. In: Danieli, Y. (ed.) International Handbook of Multigenerational Legacies of Trauma. Springer, Boston, MA. doi: 10.1007/978-1-4757-5567_33

Smedslund, G., Dalsbø, T. K., Steiro, A. K., Winsvold, A., Clench-Aas, J. (2007). Cognitive Behavioral Therapy for Men who physically abuse their female partner. Campbell Systematic Reviews. http://campbellcollaboration.org/lib/

Sonkin, D.J., Martin, D. \& Walker, L. (1985). Male batterer- A treatment approach. New York, N.Y.: Springer Publishing Co.

Stith, S., Rosen, K., McCollum, E., \& Thomsen, C. (2004). Treating intimate partner violence within intact couple relationships: Outcomes of multi-couple versus individual couple therapy. Journal of Marital and Family Therapy, 30(3), 305. doi: 10.1111/j.1752-0606.2004.tb01242.x

Straus, M.A., Hamby, S.L., Boney-McCoy, S. \& Sugarman, D.B. (1996). The Revised Conflict Tactics Scale (CTS2): development and preliminary psychometric data. Journal of Family Issues 17, 283-316. doi: 10.1177/019251396017003001

Straus, M. A., Hamby, S. L., \& Warren, W. L. (2003). The Conflict Tactics Scales handbook. Los Angeles, CA: Western Psychological Services.

Strauss, A., \& Corbin, J. (1990). Basics of qualitative research: Grounded theory procedures and techniques. Newbury Park, CA: Sage.

Swan, S. \& Snow, D. (2003). Behavioral and psychological differences among abused women who use violence in intimate relationships. Violence Against Women, 9, 75-109. doi: 10.1177/1077801202238431

Teicher, M. (2002). Scars that won't heal: The neurobiology of child abuse. Scientific American, 286(3), 68-75. Retrieved from https://www.jstor.org/stable/26059603

Tjaden, P., \& Thoennes, N. (2000). Full report on the prevalence, incidence, and consequences of violence against women. No. NCJ-183781). Washington, D.C., US: U.S. Department of Justice. Retrieved from http://www.ojp.usdoj.gov/nij/pubs-sum/183781.htm.

Truman, J. L., \& Morgan, R. E. (2014). Nonfatal domestic violence, 2003-2012. Washington, DC: US Department of Justice. 
Tsai, B. (2000). The trend toward specialized domestic violence courts: improvements on an effective innovation. Fordham Law Review, March (68), 1285.

Uniform Crime Reports (2014). Federal Bureau of Investigation. http://www.fbi.gov/about-us/cjis/ ucr.

U. S. Department of Commerce, Economics and Statistics Administration, U.S. Census Bureau. (2011). Population distribution and change: 2000 to 2010. https://www.census.gov/prod/cen2010/briefs/c2010br-01.pdf

U.S. Department of Health and Human Services, (2018). Annual Update of the Poverty Guidelines, (2018-00814). Federal Register 83 FR 2642, 2642-2644. Retrieved from federal register.gov website: https://www.federalregister.gov/documents/2018/01/18/2018-00814/annualupdate-of-the-hhs-poverty-guidelines

U.S. Department of Health \& Human Services, National Center for Injury Prevention and Control, Centers for Disease Control, Division of Violence Prevention. (2014). Prevalence and Characteristics of sexual violence, stalking and intimate partner violence victimization-National Intimate Partner and Sexual Violence Survey, United States, 2011 Morbidity and Mortality Weekly Report Surveillance Summaries, 63(8). Retrieved from cdc.gov website: https://www.cdc.gov/mmwr/pdf/ss/ss6308.pdf

U. S. Department of Justice, Bureau of Justice Statistics (2012). Retrieved July 5, 2018. https://www.bjs.gov/index.cfm?ty=tp\&tid=94

van der Kolk, B. A. (2005). Developmental trauma disorder: Toward a rational diagnosis for children with complex trauma histories. Psychiatric Annals. 35(5), 401-408. doi: 10.3928/00485713-20050501-06

van Niekerk, T. J.\& Boonzaier, F. A. (2014). The only solution there is to fight: Discourses of masculinity among South African domestically violent men. Violence Against Women, 22(3), 271-291. doi: 10.1177/1077801214555473

Ventura, L. A., \& Davis, G. (2005). Domestic violence: Court case conviction and recidivism. Violence Against Women, 11(2), 255. doi:10.1177/1077801204271722

Violence Against Women Act of 1994, 42 U.S. Code Subchapter III $\S \S 14011$ - 14016. 
Vlassoff, C. (2007). Gender differences in determinants and consequences of health and illness. Journal of Health, Population, and Nutrition, 25(1), 47-61. PMID: 17615903.

Walker, K., Bowen, E., Brown, S. (2012). Desistance from intimate partner violence: A critical review. Aggression and Violent Behavior 18, 271-280. doi: 10.1016/j.avb.2012.11.019

Waltz, J., Babcock J., Jacobson, N. \& Gottman, J. (2000). Testing a typology of batterers. Journal of Consulting and Clinical Psychology 68(4), 658-669. doi: 10.1037/0022-006X.68.4.658

Watkins, L. E., DiLillo, D., \& Maldonado, R. C. (2015). The Interactive Effects of Emotion Regulation and Alcohol Intoxication on Lab-Based Intimate Partner Aggression. Psychology of Addictive Behaviors : Journal of the Society of Psychologists in Addictive Behaviors, 29(3), 653-663. http://doi.org/10.1037/adb0000074

Weitzman, E.A. (1999). Analyzing qualitative data with computer software. Health Services Research, 34 (5 Part 2), 1241-1263. https://www.ncbi.nlm.nih.gov/pubmed/10591282

White, H. R. and Widom, C. S. (2003), Intimate partner violence among abused and neglected children in young adulthood: The mediating effects of early aggression, antisocial personality, hostility and alcohol problems. Aggr. Behav., 29: 332-345. doi: $\underline{10.1002 / a b .10074}$

Whitfield, C. L., Anda, R. F., Dube, S. R., \& Felitti, V. J. (203). Violent childhood experiences and the risk of intimate partner violence in adults: assessment in a large health maintenance organization. Journal of Interpersonal Violence 18 (2), 166-185. doi: 10.1177/0886260502238733

Widom, C. S. (1989). Does violence beget violence? A critical examination of the literature. Psychological Bulletin, 106(1), 3-29. doi: 10.1037/0033-2909.106.1.3

Wood, J. T. (2004). Monsters and victims: Male felons' accounts of intimate partner violence. Journal of Social and Personal Relationships, 21(5), 555-576 doi:10.1177/0265407504045887

Yllo, K. (2005). Through a feminist lens. In Current Controversies on Family Violence Loseke, Gelles \& Cavanaugh (Eds.). 


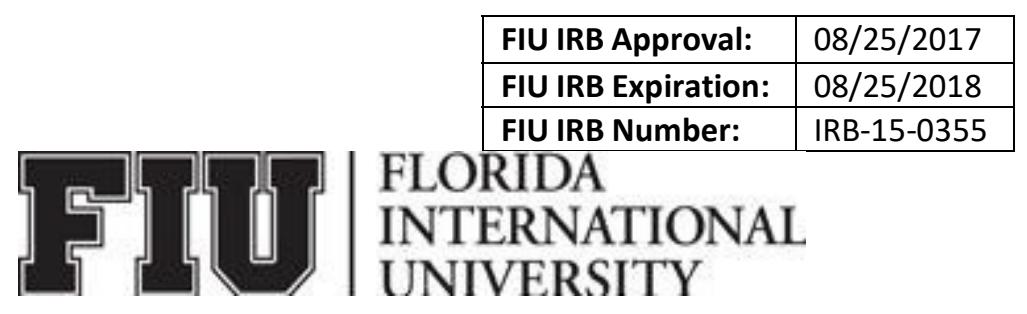

\author{
ADULT CONSENT TO PARTICIPATE IN A \\ RESEARCH STUDY Male Offenders' Perspectives on \\ Contextual and Proximal Events Associated with \\ Incidents of Domestic Violence
}

\title{
PURPOSE OF THE STUDY
}

You are being asked to be in a research study. The purpose of this study is to gather information

about men's views of their actions and their views of the events surrounding the incidents of domestic violence that resulted in their arrests, as well as to gather their thoughts and ideas about what would be helpful to families affected by domestic violence.

\section{NUMBER OF STUDY PARTICIPANTS}

If you decide to be in this study, you will be one of approximately 25 people in this research study.

\section{DURATION OF THE STUDY}

Your participation will require 45-60 minutes.

\section{PROCEDURES}

If you agree to be in the study, we will ask you to do the following things:

1. Talk about the domestic violence incident that resulted in your arrest. In particular, to talk about what disagreements are usually like in your relationship, what happened in general on the day of the incident, what happened immediately before the incident, your point of view about what caused the incident, what it was like after the arrest, and what you think would be helpful to you in programs designed to assist people in domestic violence relationships.

In addition, we will ask you to talk about how disagreements were handled in your family when you were growing up and conflicts you had with others when you were growing up and now.

2. Your participation is anonymous. We will ask you to choose an alias (name that is not your real name) to use during the study so that we will never know your real name and none of the study documents will contain your real name. However, you have the 
right to use your name and signing a written version of this Adult Consent to

Participate in Research Study. Do you wish to be linked to the

study using your real name? $\quad$ YES _ NO

(If yes, a written Adult Consent to Participate in Research Study will be provided, explained,read aloud if desired, with opportunity to ask questions and signature will be obtained.)

If no, please select an alias first name to be used in the study:

3. We will use a tape recorder to record your participation in the study. The reason we will tape record your participation is so that we have an accurate record of your comments.

4. There is one short questionnaire in the study. You can choose to answer the questions yourself with pen and paper that we will provide, or you can choose to have us read the questions to you and mark the answers you provide.The anonymous short questionnaire is about your age, ethnicity, occupation, education and marital status.

\section{RISKS AND/OR DISCOMFORTS}

The following risks may be associated with your participation in this study:

Recalling and talking about the domestic violence incident can be emotionally distressing.

\section{BENEFITS}

The following benefits may be associated with your participation in this study:

The opportunity to express your experience and viewpoints in a respectful and non-judgmental setting may be beneficial — especially since your arrest was a negative experience in which it was judged that there was probable cause that you committed the offense of domestic violence. This study gives you an opportunity to talk about what it was like for you and your thoughts about what would be helpful to families affected by domestic violence in a respectful, non- judgmental setting.

Domestic violence is a serious problem in the United States that affects thousands of families.

Not much is known about how to help families affected by domestic violence. In particular, there is not much information from men who have been charged with domestic violence offenses. This study aims to gather information from men who have been charged with domestic violence offenses to learn about their experiences, points of view, and ideas about what might be helpful to reduce domestic violence. Your paprticipation 
can contribute to learning about how best to help families affected by domestic violence.

\section{ALTERNATIVES}

There are no known alternatives available to you other than not taking part in this study. However, any significant new findings developed during the course of the research which may relate to your willingness to continue participation will be provided to you.

\section{CONFIDENTIALITY}

The records of this study will be kept private and will be protected to the fullest extent provided by law. In any

sort of report we might publish, we will not include any information that will make it possible to identify any

participants. Research records will be stored securely and only the researcher team will have access to the records.

However, your records may be reviewed for audit purposes by authorized University or other agents who will be

bound by the same provisions of confidentiality.

No personally identifiable information will be contained in or on any of the data collection materials. Participants will select aliases to use during the study instead of their real names. All data will be stored in password

protected electronic files in a locked cabinet in researcher's office.

However, if in this researcher's judgment, you make an immediate threat for risk of harm to yourself or

others, I am required by law to take steps to avoid such harm. Such steps may include breaking the promise of confidentiality and may even include calling 911 for help from police or emergency professionals. In addition, if I have reason to believe that a child is being abused, I must report this to the Florida Abuse hotline, and will do so. In these instances, I would only disclose information to the extent necessary to prevent harm.

\section{COMPENSATION \& COSTS}

You will receive a $\$ 20$ gift card for your participation in the study. If you decide to withdraw before the end of the interview, you will receive a $\$ 10$ gift card. You will not be responsible for any costs to participate in this study.

\section{RIGHT TO DECLINE OR WITHDRAW}

Your participation in this study is voluntary. You are free to participate in the study or withdraw your consent at any time during the study. Your withdrawal or lack of participation will not affect any benefits to which you are otherwise entitled. Your participation or lack of participation or withdrawal from participation in this study will not affect the 
requirement for you to comply with enrollment and participation in the Batterer Intervention Program as ordered by the court. That is, you are still obligated to participate in the Batterer Intervention Program whether or not you participate in this study.

If you consent to participate in this study, the investigator reserves the right to remove you from the study without your consent at such time that they feel it is in the best interest.

\section{RESEARCHER CONTACT INFORMATION}

If you have any questions about the purpose, procedures, or any other issues relating to this research study you may contact Sharon Aaron at 11200 S.W. $8^{\text {th }}$ Street, Room SHS270, Miami, Florida 33199,

305-348-4636, saaro001@fiu.edu.

\section{IRB CONTACT INFORMATION}

If you would like to talk with someone about your rights of being a subject in this research study or about ethical issues with this research study, you may contact the FIU Office of Research Integrity by phone at 305-348-2494 or by email at ori@fiu.edu.

\section{PARTICIPANT AGREEMENT}

Your participation in this research is voluntary, and you will not be penalized or lose benefits if you

refuse to participate or decide to stop. Do you consent to participate in this project?

I understand that I will be given a copy of this form for my records.

Printed Fictional First Name

Date 


\section{Appendix B}

\section{Demographic Information}

Pseudonym: (please pick a first name that is not your own that we can use during the interview):

1. Are you at the Advocate program for a batterer intervention program?

2. How old are you?

3. What is the highest grade you completed in school?

4. Are you employed?___ If so, Occupation:

5. What is your household income?

6. What is your race?

7. Are you of Hispanic, Latino or Spanish origin?

If yes, Country of origin:

No, not of Hispanic, Latino, or Spanish origin

8. What is your marital status?

9. What is your romantic relationship status:

(Now together, Separated, Broken Up, Not applicable)

10. If you have a current romantic relationship, do you live together in the same dwelling?

Yes No

11. In the past 12 months did you have a romantic relationship and live together in the same dwelling?

Yes No 


\section{Appendix C}

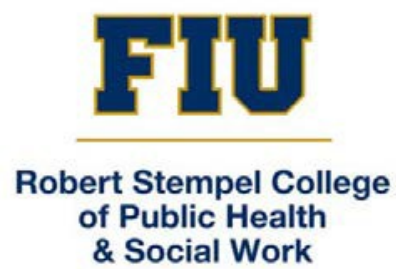

$\underline{\text { Interview Schedule }}$

I am working on a study of people who are asked to go to batterer intervention programs after they go to court. This is one of the first studies ever to ask men who have been arrested for their perspective on what happened, and what would be helpful to them at this point. Your responses are going to be very important to us, and have the potential to help others like you in the future.

I would really like to get your perspective on what you have been through, what sorts of things lead to your being here, and what you think.

We are going to be talking about the events and the person you were with when the event occurred which caused the arrest. I know that a lot has happened since then, and I have looked over the answers to the questions you filled out on the survey. Let's talk about the things that happened on the day where the events occurred that resulted in your getting arrested for domestic violence.....

Prompts:

- Talk about the violence as you see it...

- Talk about events that lead up to that...

- ...things she did that contributed...

- ...things that were going on with you that contributed...

o ...events outside home...

o ....insi

de

home... o

...with

others... 0 
...with

her...

Talk about other times when there's been this sort of conflict in the past...

Prompts:

- Tell me about the way things normally go when you and your partner are having a conflict...

- Compare to the time you got arrested

o Any worse episodes you could describe

o Any times when it went better

o Talk about things that were different....similar...

What are disagreements usually like in your relationship?

Prompts:

- They are about...

- There is usually

o shouting...

o silent treatment....

o someone leaves the room/house...

o Some physical stuff (see CTS)

- Talk about how these things get resolved...

o What happens when the

fight is over... O How do you

know the fight is over... 0

Same stuff comes up later...

Tell me about what it was like after your arrest.....

Prompts:

- Things got better / worse....

o For you... for her... for others you care about...

- Friends, family.....

- Effect on you....

So, we talked about this relationship and this incident; I wonder how disagreements were handled in your family when you were growing up....

Prompts:

- Parents together?...if not prompts for their relationships.

- Talk about conflict or fights that you remember between them... 
Talk about conflicts you have had with others when you were growing

$$
\text { up... Prompts }
$$

- Siblings

- Classmates

- Friends

- Talk about the similarities to conflicts in your relationship with your partner o Differences...

- Any times you got in physical conflicts with others growing up...

o Talk about that...

o Does it ever happen now...

I know that you have been ordered to go to a batterers intervention program. For the moment, there is not a lot of choice in the matter. But if you could design a system to help someone like yourself what would it be like?

Prompts:

- What would help you?

- What should happen to you?

o Before arrest

o After arrest

0 At sentencing

- What should happen to others

o Partner...

o Family...

- Talk about things you can think of that might have been done to keep a person like you from getting here in the first place?

I know going into a batterer's intervention program was not something you chose to do, but the basic idea is to help you not have to be here again. What would be most helpful to you so that you would not have to be here again...

Prompts:

- Things you could learn...

- Things she could learn...

- Things that could be done differently

$\bullet$

Since this is one of the first studies to try to get the perspective of men in your circumstances, I want to make sure that we have covered everything that you think is important. Is there anything that you feel is important that we have not covered?

Thank you for your time and for talking about this with me. This has been really helpful! 
VITA SHARON

AARON

1978 B.A., Psychology/Politics and Public Affairs University of Miami, Miami, Florida

1995 M.S.W., Focus: Children and Families

Barry University, Miami, Florida

2016 Doctoral Candidate

Florida International University, Miami, Florida

2001-2019 Director, Victim Empowerment Program

Florida International University

\section{SELECTED PUBLICATIONS AND PRESENTATIONS}

Battered Women's Justice Project Invited Webinar Presentation:

Batterer Intervention Programs and Victim Safety: Where do we go from here? 2017

Roxcy Bolton Rape Treatment Center invited presentation to International Chiefs of Police and Mexican Delegtion: Traumatized Victims and Law Enforcement

Investigations: the Neurobiological Impact of Trauma, Miami, Florida, June, 2017

2017 Student Affairs Administrators in Higher Education Strategies Conference Overview of an ongoing, comprehensive service model. Austin, Texas, January, 2017

Aaron, S. \& Beaulaurier, R. (2016). The need for new emphasis on batterers' intervention programs. Trauma, Violence \& Abuse. doi: 10.1177/1524838015622440.

Aaron, S., (2013). Relationships: Healthy, harmful or hazardous? Foundations for Academic Inquiry, $7^{\text {th }}$ Edition. Florida International University.

Maze, C., Aaron, S. \& Lederman, C.S., Domestic Violence Advocacy in Dependency Court: The Miami-Dade Dependency Court Intervention Program for Family Violence Handbook, National Council of Juvenile and Family Court Judges Technical Assistance Bulletin Vol. IX, April 2005.

Lederman, C., Malik, N., \& Aaron, S. (2000). Nexus between child maltreatment and domestic violence: A view from the court. Journal of the Center for Children and the Courts. 2, 129-135.

Lecklitner, G. Malik, N. Aaron, S. \& Lederman, C., (1999). Promoting the safety of abused children and battered mothers: A model dependency court intervention program. Child Maltreatment Journal of the American Professional Society on the Abuse of Children, 4, (2)175-82. 